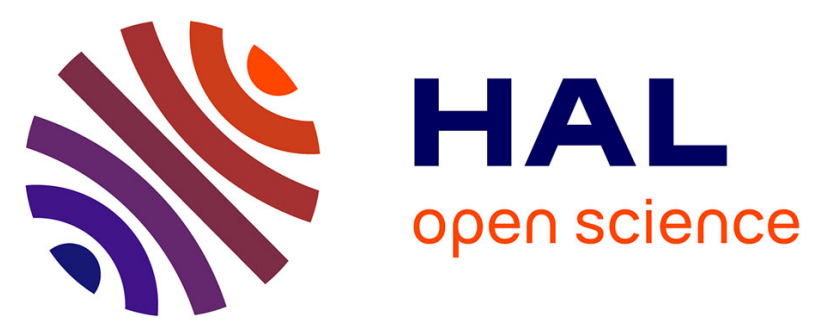

\title{
Prediction of the basic creep of concrete with high substitution of Portland cement by mineral additions at early age
}

Brice Delsaute, Jean Michel Torrenti, Stéphanie Staquet

\section{- To cite this version:}

Brice Delsaute, Jean Michel Torrenti, Stéphanie Staquet. Prediction of the basic creep of concrete with high substitution of Portland cement by mineral additions at early age: Basic creep of concrete with high slag content. Structural Concrete, 2021, 22 (1), pp.E563-E580. 10.1002/suco.201900313. hal-03161128

\section{HAL Id: hal-03161128 \\ https://hal.science/hal-03161128}

Submitted on 5 Mar 2021

HAL is a multi-disciplinary open access archive for the deposit and dissemination of scientific research documents, whether they are published or not. The documents may come from teaching and research institutions in France or abroad, or from public or private research centers.
L'archive ouverte pluridisciplinaire HAL, est destinée au dépôt et à la diffusion de documents scientifiques de niveau recherche, publiés ou non, émanant des établissements d'enseignement et de recherche français ou étrangers, des laboratoires publics ou privés. 


\title{
Prediction of the basic creep of concrete with high substitution of Portland cement by mineral additions at early age
}

\section{Basic creep of concrete with high slag content}

\section{Brice Delsaute ${ }^{1,2}$, PhD student at Université Libre de Bruxelles and Ifsttar \\ Jean-Michel Torrenti ${ }^{2}$, Director of the department Materials and Structures at Ifsttar, Professorat École nationale des ponts ParisTech.}

\author{
Stéphanie Staquet ${ }^{1}$, Associate Professor at Université Libre de Bruxelles \\ ${ }^{1}$ Université Libre de Bruxelles (ULB), BATir, Laboratory of Civil Engineering (LGC), Avenue F.D. \\ Roosevelt 50 CP194/02, 1050 Bruxelles, Belgium. \\ ${ }^{2}$ Université Paris Est, IFSTTAR, Boulevard Newton, 77447 Marne la Vallée Cedex 2, France.
}

Corresponding author: Brice Delsaute (bdelsaut@ulb.ac.be, +3226502757)

\begin{abstract}
The present work analyses the basic creep of concrete compositions for which $75 \%$ of Portland cement is substituted by limestone filler and/or blast furnace slag. Compressive creep tests are performed during and after the peak of hydration of the slag in order to track the effect of the slag on the development of the creep properties. An adapted version of the Model Code 2010 (MC2010) is used to model basic creep. It is observed that the high substitution rate of cement by limestone filler and/or slag leads to a significant change in the evolution of the viscoelastic properties of concrete till a significant degree of reaction of slag is reached. It corresponds to the end of the second peak of hydration due to slag. After the slag peak of hydration, the basic creep is similar to ordinary Portland cement concrete with equivalent water-to-binder ratio. For very early age, a new model is developed and is composed of two terms which consider the hydration of (i) Portland cement and (ii) slag in the aging of the specific creep function.
\end{abstract}

Keywords: Creep; modeling; early age; setting; mineral additions; hydration 


\section{INTRODUCTION}

For usual concrete structures built in several phases, concrete deformations are restrained during the hardening process. In case of massive structures, during the first days, a significant increase in temperature takes place due to the hydration of cement and generates compressive stresses inside concrete element. A large part of the compressive stresses are reduced thanks to the viscoelastic behaviour of cement-based materials (Benboudjema et al., 2019). For example, it is shown in (Delsaute, Boulay, \& Staquet, 2016) that, at very early age, the relaxation phenomenon is responsible for a decrease of $30 \%$ of the compressive stresses in only 5 minutes. More generally, for the design of a concrete dam, Slowik, et al. (Slowik et al., 2005) showed that at early age, the relaxation phenomenon leads to a decrease of $70 \%$ of the thermally-induced stresses in the structure. For the construction of massive structures, it is better to use binders with high slag and/or limestone filler content. The hydration process and the mechanical properties of such binder develop more slowly in comparison to conventional Potland cement. This induces lower temperature gradient within the concrete structure and thus reduces the risk of cracking of the concrete induced by the restrained of thermal deformations.

As presented in (Delsaute et al., 2017), during the hardening process and especially during the first 24 hours after setting, the Model Code 2010 overestimates the E-modulus and underestimates the creep/relaxation phenomenon of classical concrete compositions. This leads to a strong overestimation of the compressive stresses when concrete expends and to an underestimation of the tensile stresses when concrete starts to shrink. Hence, it is important to model correctly the basic creep since final setting time. However, only very scarce data are available in the literature on the viscoelastic behavior of cement-based materials at very early age. This is especially true for concrete compositions with low to medium substitution (up to 50\%) of cement by mineral additions and even more true for concrete with very high substitution rate of Portland cement. 


\section{RESEARCH SIGNIFICANCE}

In previous work, it has been shown that the logarithmic expression proposed in the Model Code 2010 is reliable to predict specific basic creep of ordinary concrete at very early age (Delsaute et al., 2017; Delsaute \& Staquet, 2019) and at later ages (Le Roy et al., 2017; J.-M. Torrenti \& Le Roy, 2017). An adapted version of the Model Code 2010 was used and it was observed that the effect of the age at loading is explicitly included by using the time derivative of the elastic modulus (Delsaute et al., 2017). In addition, this adapted version of MC2010 was used to model basic creep at elevated temperature and high stress level (J. M. Torrenti, 2017). The goal of this paper is to extend the testing and modelling methodology developed in (Delsaute et al., 2017; Delsaute, Boulay, \& Staquet, 2016; Delsaute, Boulay, Granja, et al., 2016) to study the effect of high rate of substitution $(75 \%)$ of Portland cement by mineral additions on the development of the basic creep properties since very early age till several days. More specifically, the paper aims at answer to the question: "Is the Model Code 2010 reliable to predict the basic creep behaviour of concrete with high substitution of Portland cement by mineral addition?" To answer to this question, two distinct compositions with mineral additions are compared to a reference composition with only Portland cement. The first part of the paper presents the experimental program and the preliminary results needed before having started this study. The second part of the paper focuses on the monitoring of the basic creep behaviour of the three compositions. The third part of the paper is related to the modelling of the basic creep with the adapted version of the Model Code 2010.

\section{MATERIALS AND METHODS}

\subsection{Concrete compositions}

The substitution of Portland cement by blast-furnace slag (BFS) and limestone filler is studied on three concretes for which mix proportions are given in Table 1. For each composition, the aggregate and water content is the same, only the nature of the binder changes. The first composition is a reference concrete for which the binder is only composed of Portland cement. In the second 
composition and in the third composition, $75 \%$ of the Portland cement is replaced by BFS and in the third composition by BFS (50\%) and limestone filler (25\%). These compositions are respectively called C-REF, C-BFS and C-SCM. All materials come from the same batch of production. The chemical compositions of the Portland cement, the BFS, the limestone filler and the gypsum content are presented in (Jérôme Carette \& Staquet, 2016b). Sand and gravel were oven-dried. The effective water-to-binder ratio $\mathrm{W}_{\mathrm{eff}} / \mathrm{B}$ is 0.34 for each composition. However, due of the presence of limestone filler, the effective water to equivalent binder ratio $\mathrm{W}_{\text {eff }} / \mathrm{B}_{\mathrm{eq}}$ is different for the composition C-SCM and is equal to 0.45 . The equivalent binder content is defined in Equation 1 according to the European standard EN 206-1.

$B_{\text {eq }}=$ Cement $+k \cdot$ Limestone

The parameter $\mathrm{k}$ is the activity coefficient of limestone filler given by the standard $(\mathrm{k}=0.25)$. The mixing procedure is the same for each concrete mixture and is as followed: gravel and sand are mixed during (20 s), $20 \%$ of water is added (20 s mixing), binder is added (30 s mixing) and then the rest of the water is added (150 s mixing). The speed is kept constant (300 rpm). The setting was determined by monitoring the transmission of the ultrasound p- and s-waves through concrete according to the method developed in ( Carette \& Staquet, 2016a; Saleh, Carette, Delsaute, \& Staquet, 2017). The initial and final setting times according to this method are given in Table 1.

\subsection{Compressive creep rigs}

Compressive creep tests were performed on frames designed at ULB (Delsaute, Boulay, \& Staquet, 2016). The load is applied on the sample by increasing flat jack pressure with a pump till $40 \%$ of the compressive strength obtained experimentally on samples tested at the age of the creep loading. The flat jack is chosen according to the magnitude of the loading applied (Figure 1). A cell force is placed on the top of the sample. Displacements are measured with an extensometer composed by two stainless steel rings spaced of $200 \mathrm{~mm}$ and three rods in INVAR@ supporting the 3 displacement sensors (Solartron $\odot$ range $2 \mathrm{~mm}$ ) placed at $120^{\circ}$. A dummy specimen is used to monitor the thermal and autogenous strain. Thermocouples are placed inside the dummy mould and in the room in order to 
monitor the ambient temperature and the concrete core temperature. The measurements of displacement, force and temperature are sent to a computer for data recording. The sample is a cylinder with a height of $320 \mathrm{~mm}$ and a diameter of $100 \mathrm{~mm}$. After casting, samples are sealed with a plastic sheet and a plastic cover on the top and are then placed in an air-conditioning room $\left(20^{\circ} \mathrm{C}\right.$ and RH 90\%). The mould removal takes place just after setting (for the loadings at very early age) or later. Samples are then grinded on both circular end faces and surrounded by two self-adhesive aluminum sheets. The sealing has been checked by weighting the sample before and after the test with a high precision scale. No weight loss was observed. Tests are carried out in a climatic room with a temperature of $20 \pm 1{ }^{\circ} \mathrm{C}$ and a relative humidity of $50 \pm 5 \%$.

\section{EXPERIMENTAL RESULTS AND DISCUSSION}

\subsection{Experimental program}

A certain number of fundamental properties were determined before the study of the viscoelastic behaviour of the three concrete mixes: setting time, compressive strength, the E-modulus, heat flow, activation energy and volume change ( Carette \& Staquet, 2016b, 2016a; Delsaute \& Staquet, 2017). For consideration of the aging and the main temperature effects, concrete properties are expressed in function of the equivalent time (Equation 2). Equivalent time is based on the Arrhenius equation and is function of the age of the material $t$, the evolution of the temperature $T\left({ }^{\circ} \mathrm{C}\right)$, a reference temperature $T_{r}$ (here $20^{\circ} \mathrm{C}$ ), the universal gas constant $R(=8.314 \mathrm{~J} / \mathrm{mol} / \mathrm{K})$ and the apparent activation energy $E_{a}(\mathrm{~J} / \mathrm{mol})$. The apparent activation energy was defined by means of compressive strength tests at a temperature of 10 and $30^{\circ} \mathrm{C}$ ( $\mathrm{J}$ Carette, 2015) and is 36,47 and $45 \mathrm{~kJ} / \mathrm{mol}$ for the composition C-REF, C-BFS and C-SCM respectively.

$t_{e q}(t, T)=\int_{0}^{t} \exp \left(\frac{E_{a}}{R} \cdot\left(\frac{1}{273+T(s)}-\frac{1}{273+T_{r}}\right)\right) \cdot d s$

For each composition, 4 compressive creep tests with duration of few weeks were performed. The ages at loading of the creep tests were defined on basis of the results obtained from isothermal 
calorimetry tests. The heat release by the paste of the three compositions was presented in ( Carette \& Staquet, 2016a) and is shown in Figure 2. The heat release is expressed as the measured heat release by the paste divided by the mass of Portland cement and slag. For the composition C-REF, as expected ( Carette \& Staquet, 2016a; Darquennes, 2009; Gruyaert, Robeyst, \& De Belie, 2010), a strong increase of the heat release occurred during the setting period and the next few hours. A significant decrease of the heat release is observed during the first days when substituting cement by limestone filler and/or slag. Moreover, for the compositions C-BFS and C-SCM, a significant peak occurs between an equivalent age of 40 and 60 hours and is related to the slag hydration (G. De Schutter, 1999). The evolution of the heat release is very similar for the compositions C-BFS and CSCM. The substitution of $25 \%$ of slag by limestone filler in the C-SCM composition slightly affects the heat release. The first peak of heat release starts sooner and has higher amplitude than the one for the C-BFS composition. The second peak is less pronounced and occurs on a longer duration. These both differences are mainly explained by the active contribution of limestone filler at very early age and by the influence of the gypsum/slag ratio on the slag reaction ( Carette \& Staquet, 2016a). In addition, the quantity of water available for the slag and cement hydration of the C-SCM composition is higher and can result in a higher heat flow after the peak of hydration of the slag.

From these observations, it was decided to test the C-BFS and C-SCM compositions when slag is hydrating and afterwards in order to track the effect of the slag on the evolution of the viscoelastic properties. For an adequate comparison with the reference composition C-REF, each composition is tested at a same advancement degree of reaction (ADR). The advancement degree of reaction $\alpha$ is defined according to Equation 3 where $\mathrm{q}$ is the cumulated heat release and $\mathrm{q}_{\infty}$ is the cumulated heat release for an infinite time.

$\alpha\left(t_{e q}\right)=\frac{q\left(t_{e q}\right)}{q_{\infty}}$

Each composition was tested at an advancement degree of reaction of $0.38-0.45-0.6$ and 0.7 as indicated in Figure 3. The corresponding equivalent ages at loading are indicated in Table 2 as well as the values of the compressive strength and E-modulus at loading ages. 
In addition, as early age basic creep relates to both hydrations of the Portland cement and slag, a separation of both reactions has been carried out. For that purpose, the method proposed by Meinhard and Lacker (Meinhard \& Lackner, 2008) and by Gruyaert, et al (Gruyaert et al., 2010) has been used. The cumulated heat release by the slag reaction is calculated as the difference between the total cumulated heat release of the binder and the cumulated heat release by the Portland cement with consideration of the cement-binder ratio. However, it is not possible to directly fit the evolution of the total heat release during the first hours. During this period the slag reaction is negligible and only the hydration of the Portland cement is to be considered. In addition, the reaction of the cement is enhanced by the presence of slag (Escalante-Garcia \& Sharp, 2004). Therefore, a corrective factor is used to amplify the magnitude of the reaction of the Portland cement (1.25 for the C-BFS composition and 1.5 for the C-SCM composition). Then, it is possible to define the degree of reaction of both Portland cement and slag separately with consideration of the heat release for an infinite time of the Portland cement $q_{\infty, P}$ (based on the heat release by the reference composition) and the slag $q_{\infty}-q_{\infty, P}$ as expressed in Equation 4. In this equation, the index $\mathrm{P}$ and $\mathrm{S}$ correspond to the Portland cement and the slag respectively.

$\alpha\left(t_{e q}\right)=\frac{q_{P}\left(t_{e q}\right)}{q_{\infty, P}}+\frac{q\left(t_{e q}\right)-q_{P}\left(t_{e q}\right)}{q_{\infty}-q_{\infty, P}}=\alpha_{P}\left(t_{e q}\right)+\alpha_{S}\left(t_{e q}\right)$

The result of this decoupling is shown in Figures 4 and 5. For both C-BFS and C-SCM compositions, the cumulated heat release by the slag starts to increase at an age of around 20 hours. The amplitude of the slag heat release at an age of 7 days is 105 and $98 \mathrm{~J} / \mathrm{g}$ for the composition C-BFS and C-SCM respectively. For each loading age, the degree of reaction of slag $\alpha_{S}$ and Portland cement $\alpha_{P}$ is presented in Table 2. The degree of reaction of the slag at the loading ages is between 0.18 and 0.67 for the composition C-BFS, while it is between 0.15 and 0.66 for the composition C-SCM. 


\subsection{Experimental results}

The test protocol used in (Delsaute, Boulay, \& Staquet, 2016) for the compressive creep test is used for the three compositions. The compressive creep results are expressed according to the specific creep function $\mathrm{J}^{*}$ defined in Equation 5:

$J^{*}\left(t, t^{\prime}\right)=\frac{\varepsilon_{t o t}\left(t, t^{\prime}\right)-\varepsilon_{s h}(t)}{\sigma}$

where $t$ is the age of concrete, $t^{\prime}$ is the age at loading, $\varepsilon_{t o t}$ is the total strain of the loaded specimen, $\varepsilon_{s h}$ is the strain of the dummy specimen and $\sigma$ is the stress applied on the loaded specimen.

\subsubsection{Autogenous strain}

First, the evolution of the autogenous strain (without external loading) of the dummy specimen for each composition is presented in Figure 6. The autogenous strain of the C-REF and C-SCM compositions obtained with the BTJADE device (Boulay, 2012) and presented in detail in a previous study (Delsaute \& Staquet, 2017) are also shown in Figure 6. The evolution of the strain is set to zero at an equivalent age of 19,41 and 39 hours for the composition C-REF, C-BFS and C-SCM respectively. This corresponds to the age of the first loading applied on each composition. The strains drawn with continuous lines correspond to the autogenous strains of the dummy specimen and those drawn with dashed lines were monitored with the BTJADE device. On Figure 6, the continuous and dashed lines are very close. Thanks to the thermal regulations used before and during testing, very limited temperature variations occurred in the samples, even during the hydration peaks. For the reference composition only, shrinkage is monitored at 19 hours of age whereas swelling is first monitored till an equivalent age of 56 and 67 hours for the C-BFS and C-SCM compositions respectively. The impact of substitution of Portland cement by limestone filler and/or slag on the evolution of the autogenous strain is highlighted by the initial swelling. For the C-BFS and C-SCM compositions, a high amount of ettringite is formed and is one of the cause explaining the swelling according to ( Carette, Joseph, Cizer, \& Staquet, 2018). In addition, as the limestone filler is inert, the 
effective water-to-equivalent binder ratio of the C-SCM mix is higher than the one of two other mixes. This difference explains the later development of the self-desiccation and the subsequent autogenous shrinkage in the C-SCM mix which is induced by the higher quantity of water available for hydration leading to a higher relative humidity. Courard et al. (Courard \& Michel, 2014) have already observed this decrease in the amplitude of the autogenous shrinkage when replacing slag by limestone filler. Moreover, during the swelling period, the E-modulus of the C-SCM mix is lower than the C-BFS mix (Jérôme Carette \& Staquet, 2016b). When considering a lower E-modulus and higher water content simultaneously, it can explain the longer apparent evolution and higher magnitude of the swelling strains for the C-SCM composition. After the peak of swelling, mainly selfdesiccation takes place and shrinkage starts. Autogenous shrinkage is mainly function of the evolution of the pore size distribution, the chemical shrinkage and the internal relative humidity. For mix with high substitution of Portland cement by limestone filler and/or slag content, Bouasker, et al. (Bouasker et al., 2014) found lower chemical shrinkage and a higher quantity of small pore sizes. After the peak of swelling, a higher reactivity of the slag occurs in comparison to the one of the Portland cement (see Figure 2 and Table 2). In addition, according to the Laplace law, higher tensile stresses develop in smaller pores. Because of both reasons, higher shrinkage strains are observed during this period in the C-BFS and C-SCM mixes.

\subsubsection{Basic creep}

Results of the specific creep function are presented in Figure 7. For each composition, the effect of the age at loading is strongly marked in the evolution of the specific creep especially for the compositions C-BFS and C-SCM. The impact of the replacement of $75 \%$ of Portland cement by slag depends on the age at loading. For very early age loading, before the peak of slag hydration, the magnitude of the specific creep is strongly affected by the presence of slag. For a total advancement degree of reaction of 0.38 , the degree of reaction of the slag and the Portland cement is 0.18 and 0.58 respectively and the specific creep is 2 times larger for the composition C-BFS in comparison to the reference one. For a total advancement degree of reaction of 0.7 , the degree of reaction of slag and cement is 0.67 and 0.76 and the magnitude of the specific creep is lower than the reference composition without slag. The 
differences of magnitude of the specific creep are correlated to the degree of reaction of the slag which is between 0.18 and 0.67 while the degree of reaction of the cement is between 0.58 and 0.76 (see section 4.1). Therefore, it is observed that the presence of slag increases the magnitude of the basic creep at very early age and decreases its amplitude after the peak of hydration of slag. Several authors (Brooks \& Neville, 1992; Chern \& Chan, 1989; E. Tazawa and S. Tanaka., 1989; Li \& Yao, 2001) have already shown that the presence of slag reduces the amplitude of the basic creep on hardened concrete and it is especially marked at later ages (Özbay et al., 2016). In term of kinetic, a difference is also observed for the compositions C-REF and C-BFS. The short term creep evolves faster for the C-BFS composition whereas the long term creep evolves faster for the C-REF composition. Such observation was already done by Brooks, et al. (Brooks et al., 1992) on hardened concrete for which Portland cement was replaced at 30 to $70 \%$ by slag. The substitution of $25 \%$ of slag by limestone filler increases the magnitude of the specific creep. A factor between 2 and 3 is obtained between the compositions C-BFS and C-SCM whatever the total advancement degree of reaction at loading. The degree of reaction of the Portland cement and the slag is also very similar for both compositions (Table 2). The amplitude of the specific creep of the C-SCM composition is more than 4 times higher at very early age than the one of the composition C-REF. This factor decreases when the advancement degree of reaction increases. As for the C-BFS composition, this is mainly driven by the slag reaction degree which varies more than the one of the Portland cement. In term of kinetic, a difference is also observed for the compositions C-SCM and C-BFS. The long term creep evolves faster for the C-SCM composition. These lasts observations related to the difference of kinetics between the three compositions are highlighted on the appendix.

\subsection{Discussions}

No specific consensus exists about the physical mechanisms governing the basic creep. Several theories were developed to clarify mechanisms related to basic creep according to the many studies reported in the past (Atrushi, 2003; Briffaut et al., 2012; Geert De Schutter, 2004; Forth, 2014; Gutsch, 2002; Laplante, 1993; Le Roy, 1995; Tamtsia et al., 2004). As explained in (Delsaute et al., 2017), globally each theory can be linked to two mechanisms: direct mechanisms linked to the cement 
paste and responsible of the highest part of the creep amplitude and indirect mechanisms linked to the heterogeneity of the concrete. Direct mechanisms are related to the water mobility and to the solidification of the material and can be separated in short and long terms phenomena (Acker \& Ulm, 2001; Bernard et al., 2003; Ulm et al., 1999). The short term phenomenon is linked to a stress-induced water movement towards the largest diameter pores and to the solidification (Bažant et al., 1997; Bazant \& Prasannan, 1989) of the material. The long term phenomenon is related to viscous flow in the hydrates.

In case of replacement of cement by slag, several changes occur in the binder matrix. When submitting to drying, the incorporation of slag leads to higher water mass loss at early age. Ishida, et al. (Ishida et al., 2011) have observed that it is more marked at very early age and for high replacement of Portland cement by slag. This is an indicator of the higher water mobility inside the binder matrix composed with slag at early age. In addition, the evolution of the E-modulus is lower for concrete composition with slag. Therefore, the solidification of the material under load is lower for slag composition. The higher water mobility and lower rate of the E-modulus at early age are related to the lower slag reaction degree in comparison to the one of the Portland cement and it can explain the higher short term creep of concrete composition with slag.

When substituting slag by limestone filler, at early age, the water mobility is increased by the higher water content and the rate of the evolution of the E-modulus is decreased ( Carette \& Staquet, 2016b). The higher water mobility and lower rate of the evolution of the E-modulus at early age can explain the higher short term creep of concrete composition when substituting slag by limestone filler. The long term creep is related to the slippage between cement gels. Slippage can occur between the adjacent C-S-H layers. The presence of slag can strengthen the Van der Waals force between particles of cement gels in the concrete (Xinjie et al., 2015). In addition, the presence of slag decreases the porosity, increases the formation of C-S-H and densifies the binder matrix at later ages (Mindess et al., 2003). Thus, slag reduces the slippage between cement gels and the subsequent long term basic creep deformation. Moreover, the presence of slag can improve the mechanical performances of the interfacial transition zone (ITZ) between the aggregate and the cement paste (Carles-Gibergues, 1981; 
Gao et al., 2005). A reduction of the number and length of the micro-cracks in the ITZ and the subsequent basic creep deformation is therefore expected (Xinjie et al., 2015). When replacing slag by limestone filler, long term creep increases. This can be attributed to the decrease of the reactive material (slag, clinker) content and the rising of the effective water-to-equivalent binder ratio.

It should be also noticed that some unexpected results are obtained with the composition C-SCM. For results obtained at a total advancement degree of reaction of 0.38 and 0.45 , an increase in the amplitude and the kinetic of the specific creep is observed when the total advancement degree of reaction increases.

To understand the differences of amplitude between each composition occurring during the first hours after loading, mainly two parameters can be considered: the slag reaction degree at the microscopic scale and the stiffness of the concrete at the macroscopic scale. As shown in Table 2, the degree of reaction of the slag and the E-modulus vary significantly for the compositions C-BFS and C-SCM at the different ages at loading. In Figure 8, the amplitude of the specific creep function, obtained after duration of loading of 160 hours, is plotted according to the value of the E-modulus at the loading age for each composition and each age at loading. It is generally observed that the magnitude of the creep is strongly correlated to the value of the E-modulus at the age of loading. In addition, the relation between the amplitude of the specific creep and the E-modulus follows an exponential law which appears to be not directly linked to the nature of the binder.

\section{MODELLING}

\section{1._Modelling at very early age and early age}

In the present Model Code 2010 (MC2010), basic creep is expressed with a logarithmic expression and corresponds to the multiplication of an amplitude term $\varphi_{0, b c}$ linked to the mean compressive strength at an age of 28 days $f_{c m}$ (thus independent of the age at loading) and a kinetic term $\beta_{b c}$ which is function of the age at loading $\mathrm{t}^{\prime}$, the age after loading $\left(\mathrm{t}-\mathrm{t}^{\prime}\right)$ and the type of cement $\alpha_{C}$. 
$\varphi\left(t, t^{\prime}\right)=\varphi_{0, b c}\left(f_{c m}\right) \cdot \beta_{b c}\left(t, t^{\prime}\right)=\frac{1.8}{\left(f_{c m}\right)^{0.7}} \cdot \ln \left(\left(\frac{30}{t_{0, a d j}}+0.035\right)^{2}\left(t-t^{\prime}\right)+1\right)$

$t_{0, a d j}=t^{\prime} \cdot\left(1+\frac{9}{2+t^{\prime 1.2}}\right)^{\alpha_{C e m}}$

where $\alpha_{C e m}$ depends on the type of cement and is equal to 1 for CEM $52.5 \mathrm{~N}$. In Figure 9, results from MC2010 are compared to the experimental results obtained on the reference composition CREF. For each age at loading, the predicted values of MC2010 are relatively close to the experimental results. Similar observations have already been done for an ordinary concrete with similar E-modulus values at the age of loading (Delsaute et al., 2017).

It is possible to improve the modelling of the specific creep function for very early age loading by adapting the effect of the age at loading in the model. The MC2010 model is then simplified (Le Roy et al., 2017; J.-M. Torrenti \& Le Roy, 2017) as shown in Equation 8, where the parameter C is related to the global amplitude of the creep, independent of the age at loading, and is expressed in MPa. The parameter $\tau$ is function of the age at loading and the composition, and is expressed in [d].

$\mathrm{J}^{*}\left(\mathrm{t}, \mathrm{t}^{\prime}\right)=\frac{1}{\mathrm{C}} \cdot \ln \left(1+\frac{\mathrm{t}-\mathrm{t}^{\prime}}{\tau}\right)$

Results of the modelling with the adapted MC2010 are presented in Figure 10 for the composition CREF. A very good agreement is obtained between the experimental results and the predicted values whatever the age at loading. To quantify the efficiency of the Model Code 2010 and the adapted version, the error term $\xi$ has been computed and is defined by considering the experimental and modeling values of the specific creep for each loading at the same time after loading according to Equation $9 . \mathrm{N}_{\mathrm{c}}$ and $\mathrm{N}_{\mathrm{p}}$ are respectively the number of loadings and the number of measuring points for each loading. The error $\xi$ is 2.4E-6 MPa-1 for the MC2010 and 6.0E-7 MPa-1 for the adapted MC2010. The error is then divided by a factor 4 with the adapted version. 
$\xi=\sqrt{\frac{1}{N_{L} \cdot N_{P}} \sum_{i=1}^{N_{L}} \sum_{j=1}^{N_{P}}\left(\mathrm{~J}_{\text {exp }}^{*}\left(\mathrm{t}_{\mathrm{i}}+t_{j}, \mathrm{t}_{\mathrm{i}}\right)-\mathrm{J}_{\text {mod }}^{*}\left(\mathrm{t}_{\mathrm{i}}+t_{j}, \mathrm{t}_{\mathrm{i}}\right)\right)^{2}}$

For the C-BFS and C-SCM compositions, the best fitted values with the adapted MC2010 are presented in Figure 11 (dashed lines). Such logarithmic expression is not able to fit, at the same time, the basic creep during the first days after loading and the one corresponding to long duration of loading for very early age loadings. Therefore, only creep results obtained after one or two days of loading were considered for concrete loaded at very early age (age at loading less than or equal to a total advancement degree of reaction of 0.45 ) for the determination of the parameters $\tau$ and $\mathrm{C}$. When considering only this part of the data for early age loadings, it can be seen that a good agreement is obtained between experimental results and the modelling particularly for loadings applied at later ages and after 1 or 2 days of loading for very early age loadings as shown in Figure 11 (dashed lines). Such way to model the basic creep leads, at very early age, to an overestimation of the basic creep during the first days after loading. The values of the parameter $\boldsymbol{\tau}$ and the inverse of the derivative of the Emodulus for the different age of loading are given in Table 3. The value of the parameter $\boldsymbol{\tau}$ is plotted according to the inverse of the derivative of the E-modulus in Figure 12 for each composition. Predictive values obtained with MC2010 are also presented. For the composition C-REF, a very good agreement is obtained between the optimized values fit on the experimental results and the predicted values given by MC2010. For the composition C-BFS and C-SCM, the results obtained for an advancement degree of reaction of 0.6 and 0.7 are relatively close to the results obtained for the reference composition especially for the composition C-SCM. The values of $\boldsymbol{\tau}$ obtained for the C-BFS are slightly lower. On the other hand, the values of $\boldsymbol{\tau}$ obtained for an advancement degree of reaction of 0.38 and 0.45 are strongly lower than the values obtained for the C-REF composition. In comparison, results of an ordinary concrete (Delsaute et al., 2017) are given also in Figure 12. The period, during which there is a divergence between the values of $\boldsymbol{\tau}$ predicted by MC2010 and the optimized values fit with the experimental results, is the same for the compositions C-BFS and CSCM and the ordinary concrete. This period stops when the inverse of the derivative of the E-modulus 
is higher than $0.14 \mathrm{GPa}^{-1}$.d or also when the E-modulus is higher than $35 \mathrm{GPa}$. As for the ordinary concrete, the relation between the parameter $\boldsymbol{\tau}$ and the inverse of the derivative of the E-modulus follows a power law. The expression is given in Equation 10 where $\mathrm{q}=2.95 \mathrm{E}+14, \mathrm{p}=-19.4, t_{E}=1 \mathrm{~d}$.GPa ${ }^{1}$ and $n=0.0546$.

$$
\left\{\begin{array}{l}
\tau=q \cdot\left(\frac{d E}{d t} \cdot t_{E}\right)^{p} \text { if } \frac{d E}{d t}>7.1 G P a \cdot d^{-1} \\
\tau=n \cdot\left(\frac{d E}{d t} \cdot t_{E}\right)^{-1} \text { if } \frac{d E}{d t} \leq 7.1 G P a \cdot d^{-1}
\end{array}\right.
$$

The amplitude parameter $\mathrm{C}$ of the adapted MC2010 is given in Table 4 for each composition. For the reference composition, the value of $\mathrm{C}$ obtained from experimental results is also compared in Table 3 to the value predicted by the Model Code 2010. Higher value of C is obtained with MC2010. The values obtained from C-BFS and C-SCM are strongly different from the reference concrete. The substitution of $75 \%$ of cement by slag increases the parameter $\mathrm{C}$ by a factor around 1.8 , whereas the replacement of cement by slag (50\%) and by limestone filler (25\%) decreases the parameter C by a factor around 1.8.

Results of the modelling with the adapted MC2010 and the values of $\tau$ and C coming from Equation 9 and Table 4 respectively are presented in Figure 13 and Figure 14 (dashed lines) for the compositions C-BFS and C-SCM respectively. A general agreement is obtained between the experimental results and the simulated ones. However, the development of the short term creep for early age loading is strongly overestimated during the first day after loading. This highlights that the current equations used to represent the basic creep cannot reproduce the behavior of early age concrete with high substitution of cement by slag and/or limestone filler.

As state in the Model Code 2010 ("Model Code 2010 - Final Draft, Volume 1," 2012) "Creep of concrete depends on the degree of hydration reached at a given age rather than on the age of concrete". For the modelling of early age creep, it is therefore recommended to integrate the degree of reaction in the model. Previous studies (G. De Schutter et al., 2015; Jiang et al., 2014) have shown that the degree of hydration can be used as an aging parameter to model the basic creep of concrete composed of blended binders for which slag and fly ash correspond each to $20 \%$ of the cement mass. 
However, as early age basic creep relates to both hydrations of the Portland cement and slag, the impact of both materials on the specific creep function is divided into two distinct terms as expressed in Equation 11. The term related to the Portland cement corresponds to the multiplication of the Equation 8 (reference concrete) and the ratio between the final heat release by the Portland cement and the final heat release by the paste. The term related to the slag paste corresponds to the multiplication of the ratio between the final heat release by the slag and the final heat release by the paste and a logarithmic expression for which an amplitude factor $\mathrm{A}$ and a kinetic factor $\mathrm{K}$ depend on the slag degree of reaction at the age of loading as expressed in Equation 11:

$$
\begin{aligned}
\mathrm{J}^{*}\left(\mathrm{t}, \mathrm{t}^{\prime}\right)=\frac{q_{P, \infty}}{q_{\infty}} & \cdot \frac{1}{\mathrm{C}} \cdot \ln \left(1+\frac{\mathrm{t}-\mathrm{t}^{\prime}}{\tau\left(\mathrm{t}^{\prime}\right)}\right)+\frac{q_{\infty}-q_{\infty, P}}{q_{\infty}} \cdot A\left(\alpha_{S}\left(\mathrm{t}^{\prime}\right)\right) \\
& \cdot \ln \left(1+(\mathrm{e}-1) \cdot\left(\frac{\alpha_{S}(t)-\alpha_{S}\left(\mathrm{t}^{\prime}\right)}{1-\alpha_{S}\left(\mathrm{t}^{\prime}\right)}\right)^{K\left(\alpha_{S}\left(\mathrm{t}^{\prime}\right)\right)}\right)
\end{aligned}
$$

For the BFS composition, the following mathematical relations are obtained for the parameter A and $\mathrm{K}:$

$A\left(\alpha_{S}\right)=0.000248 \cdot \exp \left(-4.556 \cdot \alpha_{S}\right)$

$K\left(\alpha_{S}\right)=\frac{1}{2.550+0.0102 * \exp \left(7.556 * \alpha_{S}\right)}$

For the composition SCM, the following mathematical relations are obtained:

$A\left(\alpha_{S}\right)=0.000389 \cdot \exp \left(-3.836 \cdot \alpha_{S}\right)$

$K\left(\alpha_{S}\right)=2.727 \cdot \alpha_{S}^{2}-1.817 \cdot \alpha_{S}+0.538$

Results of the modelling with Equation 11 and the values of A and $\mathrm{K}$ coming from Equations 11 to 14 are presented in Figure 13 and Figure 14 (dotted lines) for the compositions C-BFS and C-SCM 
respectively. A general very good agreement is observed between the experimental results and the mathematical expressions developed for each age at loading.

These correlations between the slag degree of reaction and the amplitude and kinetic parameters are function of the type of slag, the slag content, the water-to-binder ratio and the stress level. In addition, the validity of the model proposed must be verified for longer duration of loading.

\subsection{Modelling on hardened concretes}

As mentioned in section 4.2., Brooks, et al. (Brooks et al., 1992) have performed several creep tests in sealed conditions on hardened concretes (14 days at loading) for which Portland cement has been replaced at 30 to $70 \%$ by slag coming from 4 countries. In total 10 slag-cement concretes were tested including a reference composition containing only Portland cement. Each composition had a waterbinder ratio of 0.43 and a total aggregate-binder ratio of 4.11 . The chemical composition of each type of slag was similar. Complete details about the chemical composition of the cement and the slag are given in (Brooks et al., 1992). Concrete are referred by CXSYZ where X is the cement content in the binder expressed in percent, $\mathrm{Y}$ is the slag content in the binder expressed in percent and $\mathrm{Z}$ is the country origin of the slag (B for Belgium, UK for United Kingdom, SA for South Africa and J for Japan). For each composition, the adapted MC2010 is used to model the specific creep. In Figure 15, the experimental results and the modeling by the adapted MC2010 of the specific creep are presented. It is observed that the adapted MC2010 is able to reproduce the specific creep function with a very good accuracy on hardened concrete with each kind of slag and slag content (up to 70\%). Such good reproduction of the experimental results is related to the logarithmic evolution of the basic creep strain for long duration of loading. Therefore, it is highlighted that the long term creep of concrete composed of low, medium and high slag content follows a logarithmic trend.

From compressive strength data, the evolution of the E-modulus was defined according to Equation 16 developed by Brooks, et al. (Brooks et al., 1992) for slag concrete presented in this section. In order to define accurately the time derivative of the E-modulus, data of the E-modulus obtained with Equation 16 was fitted with the Equation 17. 
$E(t)=E_{\infty} \cdot \exp \left(-\left(\frac{p}{t}\right)^{r}\right)$

Where $E_{\infty}$ is the predicted value of the E-modulus for an infinite time, $p$ and $r$ are material constant parameters. The values of the parameters $p$ and $r$ are presented in the Table 5. The value of the parameter $\boldsymbol{\tau}$ is plotted according to the inverse of the time derivative of the E-modulus in Figure 16 for each composition. For each type of slag, it is observed that an increase of the slag content leads to a decrease of the value of the temporal parameter $\boldsymbol{\tau}$. The same effect of the slag was also observed with the C-BFS composition in comparison to the C-REF composition for composition with an advancement degree of reaction higher or equal to 0.6.

The amplitude parameter $\mathrm{C}$ of the adapted MC2010 is presented in Figure 17 for each type of slag in function of the slag content. For the reference composition without slag, the value of $\mathrm{C}$ obtained from experimental results is $179 \mathrm{GPa}$. The substitution of $30 \%$ of Portland cement by slag increases the factor $\mathrm{C}$ by a factor equal to around 1.5 for Belgium (300 GPa) and United Kingdom slag (334 GPa). When substituting 50\% of Portland cement by slag, an increase of the parameter $\mathrm{C}$ is observed for each type of slag. However, high difference is observed between the values of the parameter $\mathrm{C}$ according to the type of slag. For higher rate of substitution of Portland cement by slag, the trend is not the same for each type of slag. For the slag coming from United Kingdom, a rate of substitution of Portland cement by slag higher than $50 \%$ decreases the amplitude parameter C. While for other compositions, higher substitution rate of Portland cement by slag leads always to an increase of the parameter C till a substitution level of $70 \%$.

\section{LIMITATIONS OF THE STUDY}

The present work has been carried out at a constant curing temperature of $20^{\circ} \mathrm{C}$ and the load applied corresponds to a stress level of $40 \%$ for each age at loading. In the frame of early age cracking or 
early age prestress, several phenomena were not considered in the model and are expected to affect the early age stress development. The following physical mechanisms are not taken into account:

- The variation in temperature during the hardening process impacts the development of the microstructure and the internal relative humidity (Jensen \& Hansen, 1999). Such thermal change influences the development of the autogenous strain (Jérôme Carette \& Staquet, 2018) and impacts also the basic creep properties (Bažant et al., 2004; Hauggaard et al., 1999), it is even more true for concrete composed of blended cement (Ladaoui et al., 2011). Tests at different curing temperatures and with realistic temperature histories are needed to define how the constitutive parameters are influenced by the temperature when using limestone filler and/or slag in high substitution rate of cement.

- In case of restrained deformation, the stress level is not constant and the non-linear behavior of concrete should be considered for low stress level (Delsaute, 2016; Delsaute, Boulay, Granja, et al., 2016; Forth, 2014) and high stress level (Rossi et al., 2012; Switek et al., 2016; J. M. Torrenti, 2017). Moreover, the concrete behavior is different in tension and in compression (Atrushi, 2003; Bissonnette et al., 2007; Rossi et al., 2013) and the creep recovery should be considered. Tests at different stress levels and with different stress histories are needed to define how the constitutive parameters are influenced by the stress level and by the change in stress (tension or compression) when using limestone filler and/or slag. A Temperature Stress Testing Machine (Delsaute \& Staquet, 2020) could be used for such study.

- The properties (fineness, nature) of the slag and the limestone filler impact the early age development of the microstructure (Adu-Amankwah et al., 2019; Bourchy et al., 2020; Kadri et al., 2010; Nakamura et al., 1992) and thus the aging of the basic creep properties. Also this study was performed for a specific substitution rate of CEM I by limestone and or slag. This study should be extended to other substitution ratio.

Therefore further studies are still needed to correctly model the early age basic creep properties of concrete composed of a significant amount of limestone filler and/or slag. The difference of behavior 
under tension and compression and the temperature history are both major influencing parameters that require more in-depth knowledge to predict the basic creep in case of restrained shrinkage at early age.

\section{CONCLUSIONS}

The present work analyses the basic creep of concrete compositions for which $75 \%$ of Portland cement is substituted by limestone filler and/or blast furnace slag at very early age. Three compositions have been tested. The first composition is a reference composition for which the binder is only composed of Portland cement CEM I 52.5. For the two other compositions, the aggregate and water content is the same, only the nature of the binder changes. For the second and third composition, $75 \%$ of the Portland cement is replaced by blast furnace slag or by blast furnace slag (50\%) and limestone filler (25\%). Compressive creep tests were performed during and after the peak of hydration of the slag in order to track the effect of the slag on the development of the creep properties. Four loadings were applied for each composition. The ages at loading correspond to an advancement degree of reaction of $0.38,0.45,0.6$ and 0.7 for each composition. For concrete compositions with slag, it is observed that the basic creep is mainly driven by the slag reaction degree. For low slag reaction degree $(<29 \%)$, the magnitude of the basic creep is twice the one of the reference composition for a similar total advancement degree of reaction. On the other hand, when the slag reaction degree is higher (> 49\%), the magnitude of the basic creep becomes lower. Thus the magnitude of the basic creep is strongly influenced by the degree of reaction of the slag. The partial substitution of slag by $25 \%$ of limestone filler increases the magnitude of the basic creep whatever the slag reaction degree or the total advancement degree of reaction.

An adapted version of the Model Code 2010 (MC2010) is used to model basic creep. It is possible to model accurately the specific creep especially for hardened concrete due to the logarithmic trend of the specific creep function for concrete composed of slag and Portland cement. It is observed that the replacement of Portland cement by slag leads generally to an increase of the amplitude parameter $\mathrm{C}$ and a decrease of the temporal parameter $\boldsymbol{\tau}$ of the adapted MC2010. For very early age, creep is 
overestimated during few days after loading for compositions with slag and limestone filler when using the adapted version of MC2010. This drawback can be corrected by adding a logarithmic law to the adapted version of MC2010 which considers the slag degree of reaction at the age of loading and during the loading. Therefore, the specific creep function is divided in two terms which are related to the (i) Portland cement and (ii) slag hydration.

\section{DATA AVAILABILITY STATEMENT}

The data that support the findings of this study are available from the corresponding author upon reasonable request.

\section{APPENDIX}

The influence of aging on the specific creep function is observed in the change of amplitude and kinetics for the different age at loading (Figure 7). The decrease of the amplitude is inversely proportional to the age at loading and the elastic modulus (Figure 8). When each specific creep curve is normalized by the specific creep value obtained at an age after loading of 1 hour (Figure A.1), it is observed that:

- For short duration of loading $(<1 \mathrm{~h})$, the kinetic is similar for each age at loading for a same composition and thus no aging effect is observed for a short duration loading on the kinetic of the specific creep. This was already observed on an ordinary concrete (Delsaute, Boulay, \& Staquet, 2016) and is confirmed here for concrete composed of limestone filler and/or slag.

- For long duration loading (>100h), a faster development of the normalized specific creep curves is obtained for loading applied at later ages for each compositions. In figure A.2, the normalized specific creep curves of the three compositions are compared for a loading applied at a total advancement degree of reaction of 0.7 . The rate of the normalized specific creep is lower for the C-BFS composition in comparison to the C-REF. This shows that the replacement of Portland cement by slag reduces the long term creep. When slag is partially replaced by limestone filler (25\%), an increase of the long term creep is obtained. 


\section{REFERENCES}

Acker, P., \& Ulm, F. J. (2001). Creep and shrinkage of concrete: Physical origins and practical measurements. Nuclear Engineering and Design, 203(2-3), 143-158. https://doi.org/10.1016/S0029-5493(00)00304-6

Adu-Amankwah, S., Bernal Lopez, S. A., \& Black, L. (2019). Influence of component fineness on hydration and strength development in ternary slag-limestone cements. RILEM Technical Letters, 4, 81-88. https://doi.org/10.21809/rilemtechlett.2019.89

Atrushi, D. S. (2003). Tensile and Compressive Creep of Early Age Concrete: Testing and Modelling. $\mathrm{PhD}$ thesis, The Norwegian University of Sciences and Technology, Trondheim,Norway.

Bažant, Z. P., Cusatis, G., \& Cedolin, L. (2004). Temperature Effect on Concrete Creep Modeled by Microprestress-Solidification Theory. Journal of Engineering Mechanics, 130(6), 691-699. https://doi.org/10.1061/(ASCE)0733-9399(2004)130:6(691)

Bažant, Z. P., Hauggaard, A. B., Baweja, S., \& Ulm, F.-J. (1997). Microprestress-Solidification Theory for Concrete Creep. I Aging and Drying Effects. Journal of Engineering Mechanics, 123(11), 1188-1194.

Bazant, Z. P., \& Prasannan, S. (1989). Solidification theory for aging creep. I: Formulation. Journal of Engineering Mechanics, 115(8), 1691-1703. https://doi.org/10.1016/0008-8846(88)90028-2

Benboudjema, F., Carette, J., Delsaute, B., Honorio de Faria, T., Knoppik, A., Lacarrière, L., Neiry de Mendonça Lopes, A., Rossi, P., \& Staquet, S. (2019). Mechanical properties. In E. M. R. Fairbairn \& M. Azenha (Eds.), Thermal Cracking of Massive Concrete Structures - State of the Art Report of the RILEM Technical Committee 254-CMS (pp. 69-114). https://doi.org/10.1007/978-3-319-76617-1_4

Bernard, O., Ulm, F.-J., \& Lemarchand, E. (2003). A multiscale micromechanics-hydration model for the early-age elastic properties of cement-based materials. Cement and Concrete Research, 33(9), 1293-1309. https://doi.org/10.1016/S0008-8846(03)00039-5

Bissonnette, B., Pigeon, M., \& Vaysburd, A. M. (2007). Tensile creep of concrete: Study of its sensitivity to basic parameters. ACI Materials Journal, 104(4), 360-368.

Bouasker, M., Khalifa, N. E. H., Mounanga, P., \& Ben Kahla, N. (2014). Early-age deformation and autogenous cracking risk of slag-limestone filler-cement blended binders. Construction and Building Materials, 55, 158-167. https://doi.org/10.1016/j.conbuildmat.2014.01.037

Boulay, C. (2012). Test rig for early age measurements of the autogenous shrinkage of a concrete. Proceedings of the RILEM-JCJ International Workshop ConCrack 3, 111-122.

Bourchy, A., Barnes-Davin, L., Bessette, L., \& Torrenti, J. M. (2020). Effect of Cement Composition on Fresh State and Heat of Hydration of Portland Cement with Limestone and Slag. ACI Materials Journal, 117(1). https://doi.org/10.14359/51719079

Briffaut, M., Benboudjema, F., Torrenti, J.-M., \& Nahas, G. (2012). Concrete early age basic creep: Experiments and test of rheological modelling approaches. Construction and Building Materials, 36, 373-380. https://doi.org/10.1016/j.conbuildmat.2012.04.101

Brooks, J. J., \& Neville, A. (1992). Creep and Shrinkage of Concrete as Affected by Admixtures and Cement replacement materials. Special Publication, 135, 19-36.

Brooks, J. J., Wainwright, P. J., \& Boukendakji, M. (1992). Influence of Slag Type and Replacement 
Level on Strength Elasticity, Shrinkage and Creep of Concrete. Special Publication, 132, 13251342.

Carette, J. (2015). Towards Early Age Characterization of Eco-Concrete containing blast-furnace slag and limestone filler. PhD thesis, ULB-BATir, Brussel, Belgium.

Carette, Jérôme, Joseph, S., Cizer, Ö., \& Staquet, S. (2018). Decoupling the autogenous swelling from the self-desiccation deformation in early age concrete with mineral additions: Micro-macro observations and unified modelling. Cement and Concrete Composites, 85, 122-132. https://doi.org/10.1016/j.cemconcomp.2017.10.008

Carette, Jérôme, \& Staquet, S. (2016a). Monitoring and modelling the early age and hardening behaviour of eco-concrete through continuous non-destructive measurements: Part I. Hydration and apparent activation energy. Cement and Concrete Composites, 73, 10-18. https://doi.org/10.1016/j.cemconcomp.2016.07.002

Carette, Jérôme, \& Staquet, S. (2016b). Monitoring and modelling the early age and hardening behaviour of eco-concrete through continuous non-destructive measurements: Part II. Mechanical behaviour. Cement and Concrete Composites, 73, 1-9. https://doi.org/10.1016/j.cemconcomp.2016.07.003

Carette, Jérôme, \& Staquet, S. (2018). Unified modelling of the temperature effect on the autogenous deformations of cement-based materials. Cement and Concrete Composites, 94, 62-71. https://doi.org/10.1016/j.cemconcomp.2018.08.008

Carles-Gibergues, A. (1981). Les ajouts dans les microbétons; influence sur l'auréole de transition et sur les propriétés mécaniques. $\mathrm{PhD}$ thesis, Toulouse.

Chern, J. C., \& Chan, Y. W. (1989). Deformations of concrete made with blast-furnace slag cement and ordinary Portland cement. ACI Materials Journal, 86, 372-382.

Courard, L., \& Michel, F. (2014). Limestone fillers cement based composites: Effects of blast furnace slags on fresh and hardened properties. Construction and Building Materials, 51, 439-445. https://doi.org/10.1016/j.conbuildmat.2013.10.076

Darquennes, A. (2009). Comportement au jeune âge de bétons formulés à base de ciment au laitier de haut fourneau en condition de déformations libre et restreinte. $\mathrm{PhD}$ thesis, Université Libre de Bruxelles.

De Schutter, G. (1999). Hydration and temperature development of concrete made with blast-furnace slag cement. Cement and Concrete Research, 29, 143-149.

De Schutter, G., Yuan, Y., Liu, X., \& Jiang, W. (2015). Degree of hydration-based creep modeling of concrete with blended binders: from concept to real applications. Journal of Sustainable Cement-Based Materials, 4(1), 1-14. https://doi.org/10.1080/21650373.2014.928808

De Schutter, Geert. (2004). Applicability of degree of hydration concept and maturity method for thermo-visco-elastic behaviour of early age concrete. Cement and Concrete Composites, 26(5), 437-443. https://doi.org/10.1016/S0958-9465(03)00067-2

Delsaute, B. (2016). New approach for Monitoring and Modelling of the Creep and Shrinkage behaviour of Cement Pastes, Mortars and Concretes since Setting Time. Université Libre de Bruxelles (BATir) and Université Paris Est (IFSTTAR).

Delsaute, B., Boulay, C., Granja, J., Carette, J., Azenha, M., Dumoulin, C., Karaiskos, G., Deraemaeker, A., \& Staquet, S. (2016). Testing Concrete E-modulus at Very Early Ages Through Several Techniques: An Inter-laboratory Comparison. Strain, 52(2), 91-109. https://doi.org/10.1111/str.12172 
Delsaute, B., Boulay, C., \& Staquet, S. (2016). Creep testing of concrete since setting time by means of permanent and repeated minute-long loadings. Cement and Concrete Composites, 73, 75-88. https://doi.org/10.1016/j.cemconcomp.2016.07.005

Delsaute, B., \& Staquet, S. (2017). Decoupling Thermal and Autogenous Strain of Concretes with Different Water/Cement Ratios During the Hardening Process. Advances in Civil Engineering Materials, 6(2), 22. https://doi.org/10.1520/ACEM20160063

Delsaute, B., \& Staquet, S. (2019). Development of Strain-Induced Stresses in Early Age Concrete Composed of Recycled Gravel or Sand. Journal of Advanced Concrete Technology, 17(6), 319334. https://doi.org/10.3151/jact.17.319

Delsaute, B., \& Staquet, S. (2020). Testing Concrete Since Setting Time Under Free and Restrained Conditions. In Advanced Techniques for Testing of Cement-Based Materials (pp. 177-209). https://doi.org/10.1007/978-3-030-39738-8_6

Delsaute, B., Torrenti, J.-M., \& Staquet, S. (2017). Modeling basic creep of concrete since setting time. Cement and Concrete Composites, 83, 239-250. https://doi.org/10.1016/j.cemconcomp.2017.07.023

E. Tazawa and S. Tanaka., A. Y. (1989). Drying Shrinkage and Creep of Concrete Containing Granulated Blast Furnace Slag. Special Publication, 114, 1325-1344. https://doi.org/10.14359/2604

Escalante-Garcia, J.-I., \& Sharp, J. H. (2004). The chemical composition and microstructure of hydration products in blended cements. Cement and Concrete Composites, 26(8), 967-976. https://doi.org/10.1016/j.cemconcomp.2004.02.036

Forth, J. P. (2014). Predicting the tensile creep of concrete. Cement and Concrete Composites, 55(July), 70-80. https://doi.org/10.1016/j.cemconcomp.2014.07.010

Gao, J. M., Qian, C. X., Liu, H. F., Wang, B., \& Li, L. (2005). ITZ microstructure of concrete containing GGBS. Cement and Concrete Research, 35(7), 1299-1304. https://doi.org/10.1016/j.cemconres.2004.06.042

Gruyaert, E., Robeyst, N., \& De Belie, N. (2010). Study of the hydration of Portland cement blended with blast-furnace slag by calorimetry and thermogravimetry. Journal of Thermal Analysis and Calorimetry, 102(3), 941-951. https://doi.org/10.1007/s10973-010-0841-6

Gutsch, A.-W. (2002). Properties of early age concrete-Experiments and modelling. Materials and Structures, 35(March), 76-79. http://link.springer.com/article/10.1007/BF02482104

Hauggaard, A., Damkilde, L., \& Hansen, F. (1999). Transitional Thermal Creep of Early Age Concrete. Engineering, 125(April), 458-465. https://doi.org/10.1061/(ASCE)07339399(1999)125:4(458)

Ishida, T., Luan, Y., Sagawa, T., \& Nawa, T. (2011). Modeling of early age behavior of blast furnace slag concrete based on micro-physical properties. Cement and Concrete Research, 41(12), 1357-1367. https://doi.org/10.1016/j.cemconres.2011.06.005

Jensen, O. M., \& Hansen, P. F. (1999). Influence of temperature on autogenous deformation and relative humidity change in hardening cement paste. Cement and Concrete Research, 29(4), 567-575. https://doi.org/10.1016/S0008-8846(99)00021-6

Jiang, W., De Schutter, G., \& Yuan, Y. (2014). Degree of hydration based prediction of early age basic creep and creep recovery of blended concrete. Cement and Concrete Composites, 48, 8390. https://doi.org/10.1016/j.cemconcomp.2013.10.012 
Kadri, E. H., Aggoun, S., De Schutter, G., \& Ezziane, K. (2010). Combined effect of chemical nature and fineness of mineral powders on Portland cement hydration. Materials and Structures, 43(5), 665-673. https://doi.org/10.1617/s11527-009-9519-6

Ladaoui, W., Vidal, T., Sellier, A., \& Bourbon, X. (2011). Effect of a temperature change from 20 to $50^{\circ} \mathrm{C}$ on the basic creep of HPC and HPFRC. Materials and Structures, 44(9), 1629-1639. https://doi.org/10.1617/s11527-011-9723-Z

Laplante, P. (1993). Propriétés mécaniques des bétons durcissants: analyse comparée des bétons classiques et à très hautes performances. $\mathrm{PhD}$ thesis, Ecole Nationale des Ponts et Chaussées.

Le Roy, R. (1995). Déformations instantanées et différées des bétons à hautes performances. $\mathrm{PhD}$ thesis, Ecole Nationale des Ponts et Chaussées, Paris, France.

Le Roy, R., Le Maou, F., \& Torrenti, J. M. (2017). Long term basic creep behavior of high performance concrete: data and modelling. Materials and Structures, 50(1), 85. https://doi.org/10.1617/s11527-016-0948-8

Li, J., \& Yao, Y. (2001). A study on creep and drying shrinkage of high performance concrete. Cement and Concrete Research, 31(8), 1203-1206. https://doi.org/10.1016/S00088846(01)00539-7

Meinhard, K., \& Lackner, R. (2008). Multi-phase hydration model for prediction of hydration-heat release of blended cements. Cement and Concrete Research, 38(6), 794-802. https://doi.org/10.1016/j.cemconres.2008.01.008

Mindess, S., Young, J. F., \& Darwin, D. (2003). Concrete. rentice Hall, Pearson Education, Inc. Upper Saddle River, NJ 07458, U.S.A.

Model Code 2010 - Final draft, Volume 1. (2012). International Federation for Structural Concrete (Fib), 65, 350.

Nakamura, N., Saki, M., \& Swamy, R. N. (1992). Effect of slag fineness on the development of concrete strength and microstructure. Special Publication, 132, 1343-1366.

Özbay, E., Erdemir, M., \& Durmuş, H. I. (2016). Utilization and efficiency of ground granulated blast furnace slag on concrete properties - A review. Construction and Building Materials, 105, 423434. https://doi.org/10.1016/j.conbuildmat.2015.12.153

Rossi, P., Tailhan, J.-L., \& Le Maou, F. (2013). Comparison of concrete creep in tension and in compression: Influence of concrete age at loading and drying conditions. Cement and Concrete Research, 51, 78-84. https://doi.org/10.1016/j.cemconres.2013.04.001

Rossi, P., Tailhan, J.-L., Le Maou, F., Gaillet, L., \& Martin, E. (2012). Basic creep behavior of concretes investigation of the physical mechanisms by using acoustic emission. Cement and Concrete Research, 42(1), 61-73. https://doi.org/10.1016/j.cemconres.2011.07.011

Saleh, M., Carette, J., Delsaute, B., \& Staquet, S. (2017). Applicability of ultrasonic measurement on the monitoring of the setting of cement pastes: effect of water content and mineral additions. Advances in Civil Engineering.

Slowik, V., Schmidt D., \& Nietner L. (2005). Effect of stress relaxation on thermal stresses. Concreep 7, 411-416.

Switek, A. E., Denarié, E., \& Brühwiler, E. (2016). Early age creep and relaxation of UHPFRC under low to high tensile stresses. Cement and Concrete Research, 83, 57-69. https://doi.org/10.1016/j.cemconres.2016.01.005 
Tamtsia, B. T., Beaudoin, J. J., \& Marchand, J. (2004). The early age short-term creep of hardening cement paste: load-induced hydration effects. Cement and Concrete Composites, 26(5), 481489. https://doi.org/10.1016/S0958-9465(03)00079-9

Torrenti, J.-M., \& Le Roy, R. (2017). Analysis of some basic creep tests on concrete and their implications for modeling. Structural Concrete. https://doi.org/10.1002/suco.201600197

Torrenti, J. M. (2017). Basic creep of concrete-coupling between high stresses and elevated temperatures. European Journal of Environmental and Civil Engineering, 1-10. https://doi.org/10.1080/19648189.2017.1280417

Ulm, F.-J., Le Maou, F., \& Boulay, C. (1999). Creep and shrinkage coupling: New review of some evidence. ACI-RILEM Workshop on Creep and Shrinkage of Concrete Structures, 21-37.

Xinjie, W., Qun, X., \& Pinghua, Z. (2015). Experimental Research on the Effect of Ground Slag on Basic Tensile Creep of Early-age Concrete. The Open Construction and Building Technology Journal, 9(1), 68-72. https://doi.org/10.2174/1874836801509010068 


\section{TABLES}

Table 1 - Mixture proportions in $\mathrm{kg} / \mathrm{m}^{3}$ and materials properties of the concrete composition (Jérôme Carette \& Staquet, 2016b).

\begin{tabular}{|l|c|c|c|}
\hline & C-REF & C-BFS & C-SCM \\
\hline Sand 0/4 & \multicolumn{3}{|c|}{853} \\
\hline Gravel 6/10 & \multicolumn{3}{|c|}{210} \\
\hline Gravel 10/14 & \multicolumn{3}{|c|}{873} \\
\hline CEMI 52.5 N CE CP2 NF & 432 & 103 & 103 \\
\hline Blast furnace slag & - & 291 & 164 \\
\hline Limestone filler & - & - & 124 \\
\hline Gypsum & - & 22 & 22 \\
\hline Added water & 173 & 167 & 165 \\
\hline $\mathrm{W}_{\text {abs }} / \mathrm{B}[/]$ & & 0.40 \\
\hline $\mathrm{W}_{\text {eff }} / \mathrm{B}[/]$ & & 0.34 \\
\hline $\mathrm{W}_{\text {eff }} / \mathrm{B}_{\text {eq }}[/]$ & 0.34 & 0.34 & 0.45 \\
\hline Initial setting time $\mathrm{t}_{\mathrm{i}}[\mathrm{h}]$ & 3.5 & 6.1 & 4.6 \\
\hline Final setting time $\mathrm{t}_{\mathrm{f}}[\mathrm{h}]$ & 4.1 & 8.5 & 6.7 \\
\hline
\end{tabular}

Table 2 - Experimental program for long duration creep tests. The age at loading is defined according to the advancement degree of reaction $(\alpha)$.

\begin{tabular}{c|ccc|ccccc|ccccc}
\hline \multicolumn{10}{c}{ C-REF } & \multicolumn{10}{c}{ C-BFS } \\
\hline$\alpha$ & $\mathrm{t}_{\text {eq }}$ & $\mathrm{f}_{\mathrm{c}}$ & $\mathrm{E}$ & $\mathrm{t}_{\mathrm{eq}}$ & $\alpha_{\mathrm{c}}$ & $\alpha_{\mathrm{s}}$ & $\mathrm{f}_{\mathrm{c}}$ & $\mathrm{E}$ & $\mathrm{t}_{\text {eq }}$ & $\alpha_{\mathrm{c}}$ & $\alpha_{\mathrm{s}}$ & $\mathrm{f}_{\mathrm{c}}$ & $\mathrm{E}$ \\
{$[/]$} & {$[\mathrm{h}]$} & {$[\mathrm{MPa}]$} & {$[\mathrm{GPa}]$} & {$[\mathrm{h}]$} & {$[/]$} & {$[/]$} & {$[\mathrm{MPa}]$} & {$[\mathrm{GPa}]$} & {$[\mathrm{h}]$} & {$[/]$} & {$[/]$} & {$[\mathrm{MPa}]$} & {$[\mathrm{GPa}]$} \\
\hline 0.38 & 19 & 19.0 & 38.1 & 41 & 0.58 & 0.18 & 5.8 & 29.5 & 39 & 0.57 & 0.15 & 4.3 & 18.4 \\
0.45 & 24 & 23.6 & 40.2 & 49 & 0.62 & 0.29 & 7.8 & 36.9 & 48 & 0.62 & 0.22 & 6.1 & 22.5 \\
0.6 & 40 & 27.5 & 43.1 & 66 & 0.68 & 0.49 & 11.4 & 39.9 & 70 & 0.69 & 0.42 & 9.7 & 33.8 \\
0.7 & 71 & 32.0 & 44.6 & 120 & 0.76 & 0.67 & 20.8 & 42.2 & 118 & 0.75 & 0.66 & 16.8 & 38.9 \\
& & & & & & & & & & & & & \\
\hline
\end{tabular}


Table 3 - Value of parameter $\boldsymbol{\tau}$ from Equation 7.

\begin{tabular}{l|c|c|c|c}
\hline \multicolumn{5}{c}{ C-REF } \\
\hline $\mathrm{t}^{\prime}[\mathrm{h}]$ & 19 & 24 & 40 & 71 \\
Inverse of dE/dt [d.GPa-1] & $7.69 \mathrm{E}-02$ & $1.31 \mathrm{E}-01$ & $4.41 \mathrm{E}-01$ & $1.73 \mathrm{E}+00$ \\
$\boldsymbol{\tau}$ [d] & $4.04 \mathrm{E}-03$ & $6.84 \mathrm{E}-03$ & $5.22 \mathrm{E}-02$ & $8.76 \mathrm{E}-02$ \\
\hline \multicolumn{5}{c}{ C-BFS } \\
\hline $\mathrm{t}^{\prime}[\mathrm{h}]$ & 41 & 49 & 66 & 120 \\
Inverse of dE/dt [d.GPa-1] & $4.23 \mathrm{E}-02$ & $5.33 \mathrm{E}-02$ & $1.05 \mathrm{E}+00$ & $8.27 \mathrm{E}-01$ \\
$\boldsymbol{\tau}$ [d] & $2.71 \mathrm{E}-14$ & $1.85 \mathrm{E}-09$ & $7.19 \mathrm{E}-04$ & $2.03 \mathrm{E}-02$ \\
\hline \multicolumn{5}{c}{ C-SCM } \\
\hline $\mathrm{t}^{\prime}[\mathrm{h}]$ & 39 & 48 & 70 & 118 \\
Inverse of dE/dt [d.GPa-1] & $8.81 \mathrm{E}-02$ & $6.49 \mathrm{E}-02$ & $1.71 \mathrm{E}-01$ & $7.25 \mathrm{E}-01$ \\
$\boldsymbol{\tau}$ [d] & $9.80 \mathrm{E}-08$ & $2.47 \mathrm{E}-08$ & $3.20 \mathrm{E}-03$ & $2.13 \mathrm{E}-01$ \\
\hline
\end{tabular}

Table 4 - Values of the parameter C predicted by MC2010 and obtained by optimization of each composition (in GPa).

\begin{tabular}{|c|c|c|c|}
\hline & C-REF & C-BFS & C-SCM \\
\hline Optimized value & 255 & 455 & 140 \\
\hline Value predicted by MC2010 according to $f_{c m}$ & 315 & - & - \\
\hline
\end{tabular}

Table 5 - Values of the parameter of Equation 17

\begin{tabular}{|l|c|ccc|ccc|cc|cc|}
\cline { 2 - 11 } \multicolumn{1}{c|}{} & \multirow{2}{*}{ OPC } & \multicolumn{3}{|c|}{ slag UK } & \multicolumn{2}{c|}{ slag Belgium } & \multicolumn{2}{c|}{ slag South Afrika } & \multicolumn{2}{c|}{ slag Japan } \\
\multicolumn{1}{|c|}{} & \multicolumn{2}{c|}{ slag content [\%] } & \multicolumn{2}{c|}{ slag content [\%] } & \multicolumn{2}{c|}{ slag content [\%] } & \multicolumn{2}{c|}{ slag content [\%] } \\
\cline { 2 - 12 } & & 30 & 50 & 70 & 30 & 50 & 70 & 50 & 70 & 50 & 70 \\
\hline$E_{\infty}$ & 34.3 & 42.7 & 43.1 & 53.8 & 42.1 & 46.8 & 38.9 & 51.1 & 44.6 & 51.1 & 60.4 \\
$p$ & 1.65 & 2.03 & 4.11 & 4.67 & 1.42 & 3.01 & 2.97 & 4.91 & 7.24 & 3.75 & 7.85 \\
$r$ & 1.14 & 0.64 & 0.91 & 0.44 & 0.55 & 0.55 & 0.65 & 0.55 & 0.72 & 0.52 & 0.33 \\
\hline
\end{tabular}




\section{FIGURES}

Figure 1 - Left to right: shrinkage test setup, creep test setup and dimension of the flat jack according to the loading applied [2].

Figure 2 - Heat flow evolution from isothermal calorimetry tests. The circular markers are related to the time when compressive creep tests have started.

Figure 3 - Advancement degree of reaction ADR in function of the equivalent age. The circular markers are related to the time when compressive creep tests have started.

Figure 4 - Separation of the Portland cement and the slag reaction based on the heat release for the C-BFS composition.

Figure 5- Separation of the Portland cement and the slag reaction based on the heat release for the C-SCM composition.

Figure 6 - Evolution of the autogenous strain of the dummy specimen (the continuous lines correspond to the strain of the dummy specimen and the dashed lines are related to the autogenous strain obtained in [13])

Figure 7 - Specific creep functions for several ages at loading.

Figure 8 - Amplitude of the creep compliance after 160 hours of loading according to the E-modulus at the age of loading.

Figure 9 - Comparison between predicted value of the creep compliance obtained with MC2010 (dashed lines) and experimental results (continuous lines)

Figure 10 - Comparison between experimental creep curves (continuous lines) and creep curves predicted by an adapted version of the MC2010 (dashed lines).

Figure 11 - Specific creep and adapted MC2010 (dashed lines) of the C-BFS and C-SCM compositions

Figure 12 - Relation between the parameter $\boldsymbol{\tau}$ of the adapted MC2010 and the inverse of the E-modulus rate.

Figure 13 - Comparison between predicted value of the creep compliance obtained with the adapted MC2010 where the values of $\tau$ and $\mathrm{C}$ come from Equation 9 and Table 4 respectively (dashed lines), the two terms model (dotted lines) and experimental results (continuous lines) for the composition C-BFS.

Figure 14 - Comparison between predicted value of the creep compliance obtained with the adapted MC2010 where the values of $\tau$ and $\mathrm{C}$ come from Equation 9 and Table 4 respectively (dashed lines), the two terms model (dotted lines) and experimental results (continuous lines) for the composition C-SCM.

Figure 15 - Specific creep function and adapted MC2010 (dashed lines) of concrete compositions with different slag content and origin [26].

Figure 16 - Relation between the parameter $\boldsymbol{\tau}$ of the adapted MC2010 and the inverse of the time derivative of the E-modulus for concretes with different slag type and slag content. Results are compared to very early age and early age results presented in section 5.1. Results coming from Brooks, et al. [26] used the same legend marks as in Figure 15.

Figure 17 - Relation between the parameter C of the adapted MC2010 and the slag content for concrete with different type of slag.

Figure A.1 - Specific creep curves normalized at an age after loading of 1 hour

Figure A.2 - Specific creep curves normalized at an age after loading of 1 hour for an advancement degree of reaction at loading of 0.7 


\section{FIGURES}

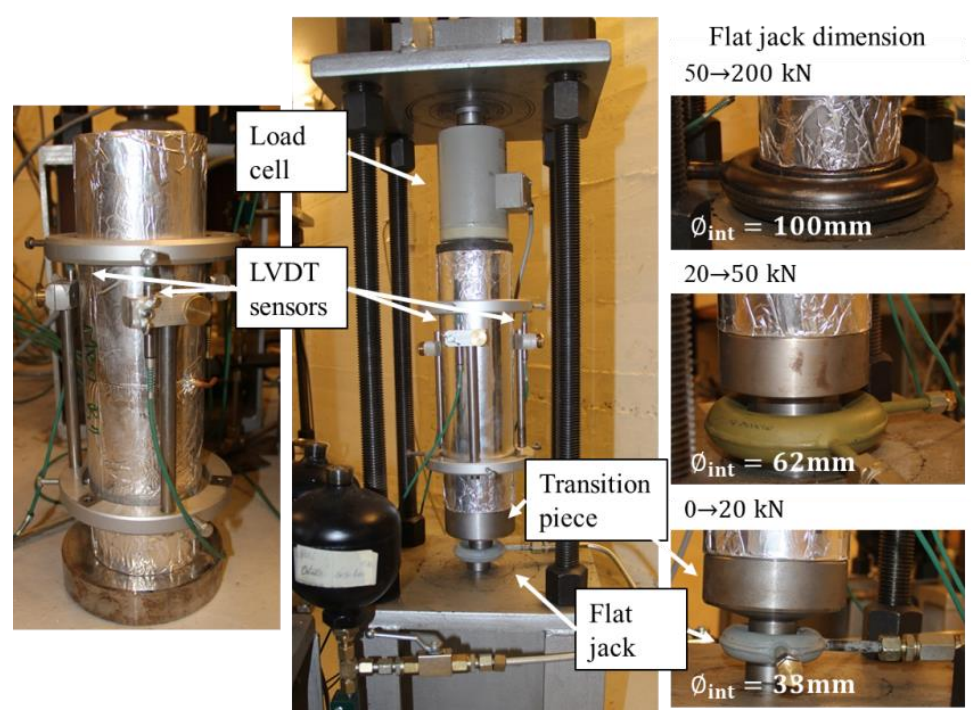

Figure 1 - Left to right: shrinkage test setup, creep test setup and dimension of the flat jack according to the loading applied [2].

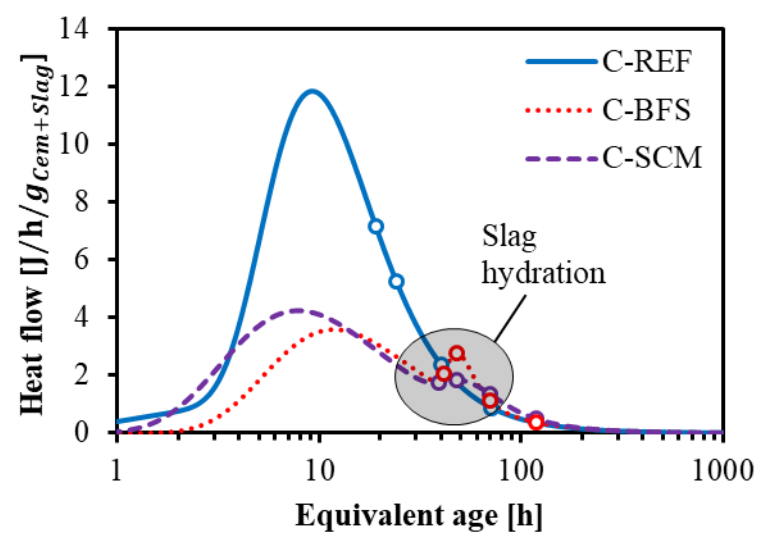

Figure 2 - Heat flow evolution from isothermal calorimetry tests. The circular markers are related to the time when compressive creep tests have started.

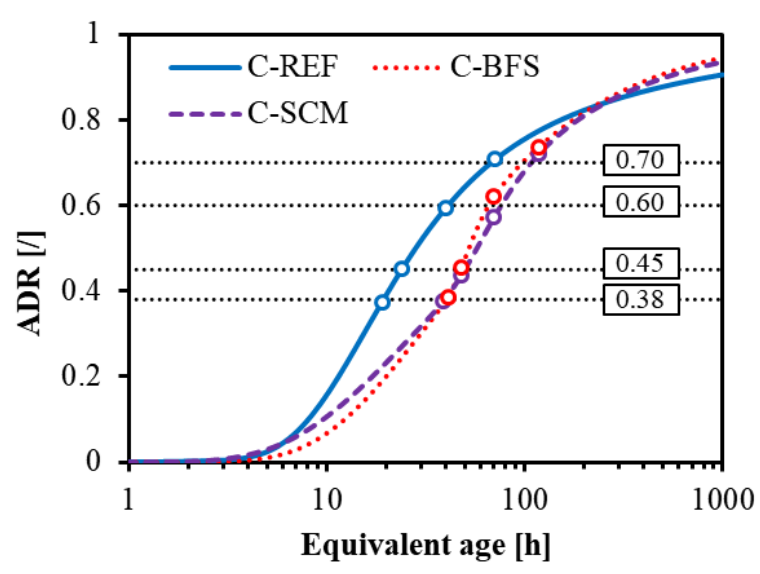

Figure 3 - Advancement degree of reaction ADR in function of the equivalent age. The circular markers are related to the time when compressive creep tests have started. 


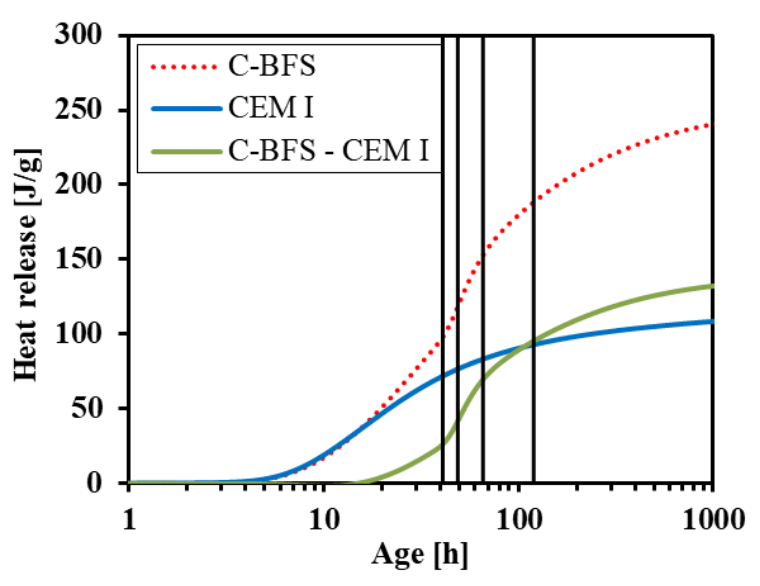

Figure 4 - Separation of the Portland cement and the slag reaction based on the heat release for the C-BFS composition. Vertical lines correspond to the age at loading.

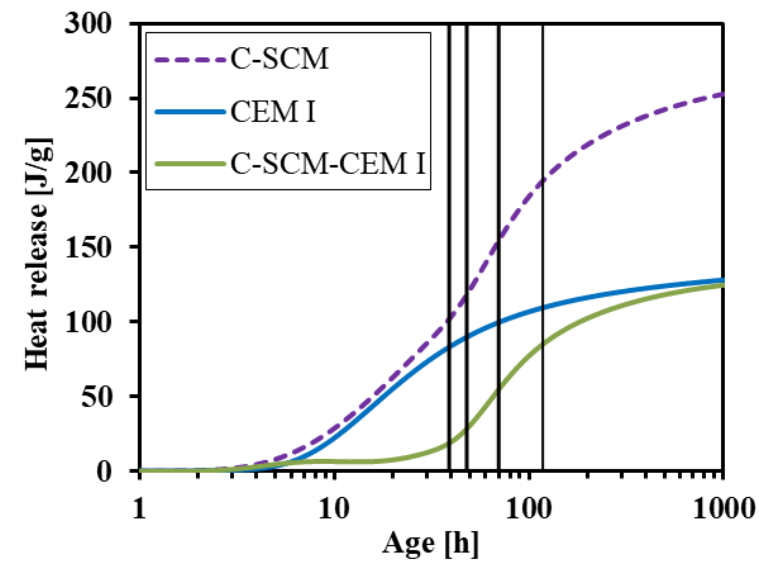

Figure 5- Separation of the Portland cement and the slag reaction based on the heat release for the C-SCM composition. Vertical lines correspond to the age at loading.

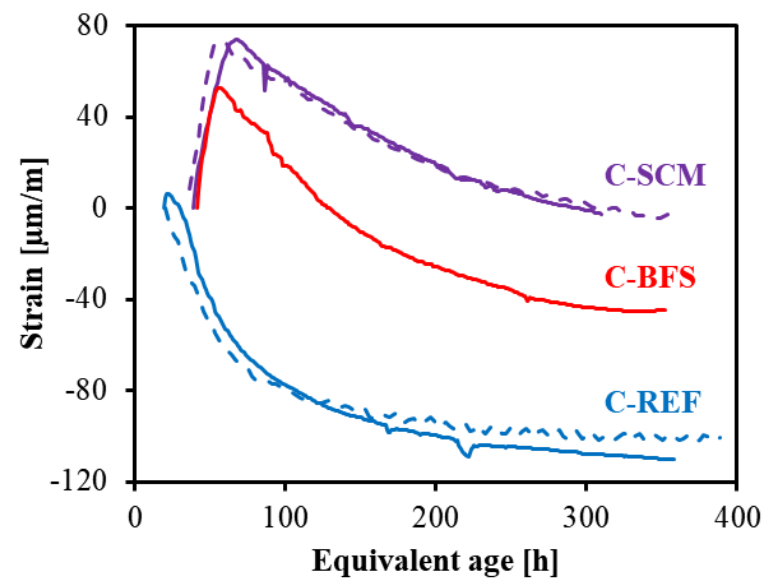

Figure 6 - Evolution of the autogenous strain of the dummy specimen (the continuous lines correspond to the strain of the dummy specimen and the dashed lines are related to the autogenous strain obtained in 

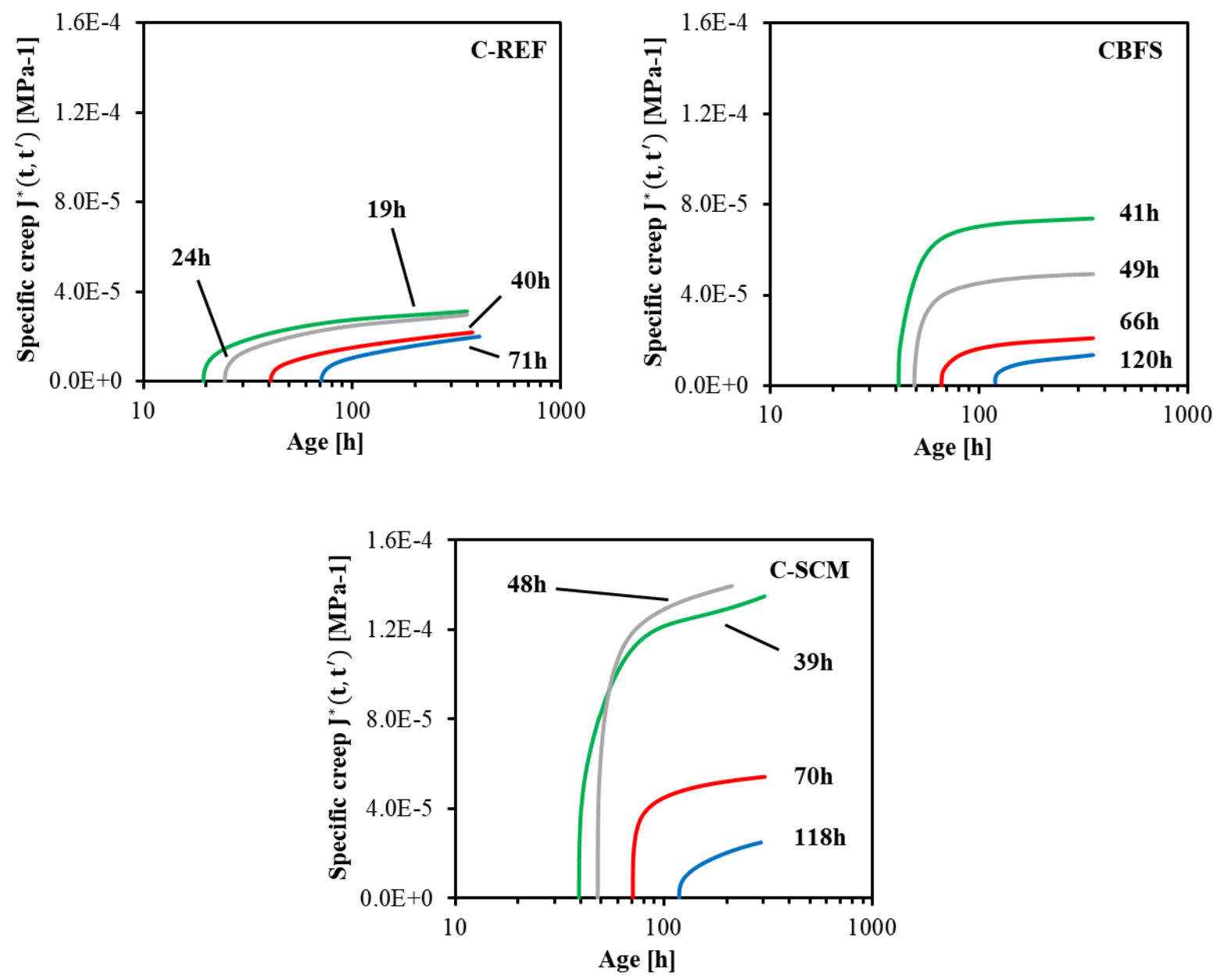

Figure 7 - Specific creep functions for several ages at loading.

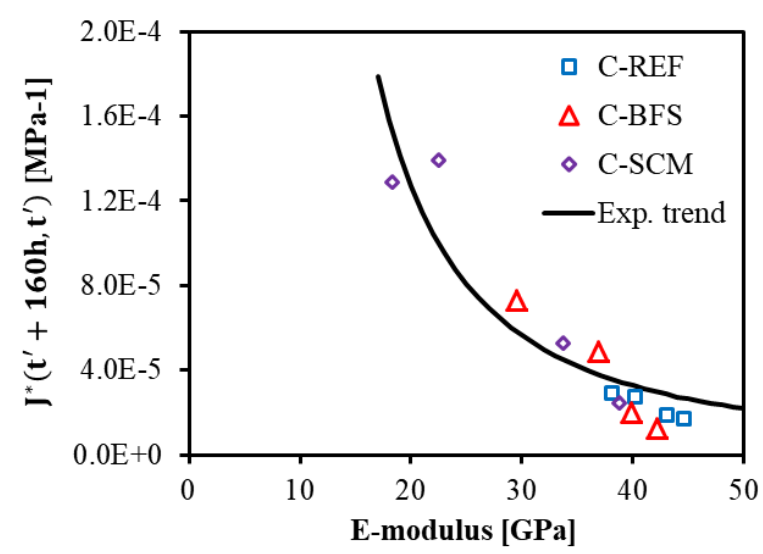

Figure 8 - Amplitude of the creep compliance after 160 hours of loading according to the E-modulus at the age of loading. 


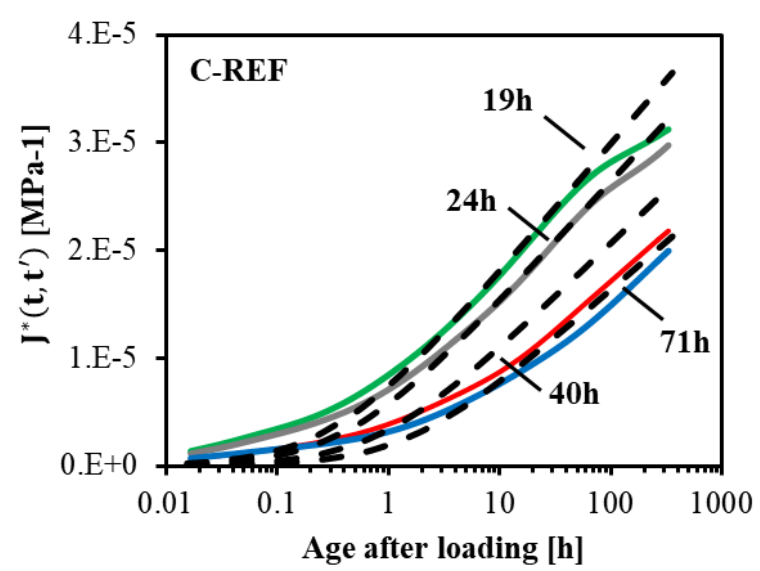

Figure 9 - Comparison between predicted value of the creep compliance obtained with MC2010 (dashed lines) and experimental results (continuous lines)

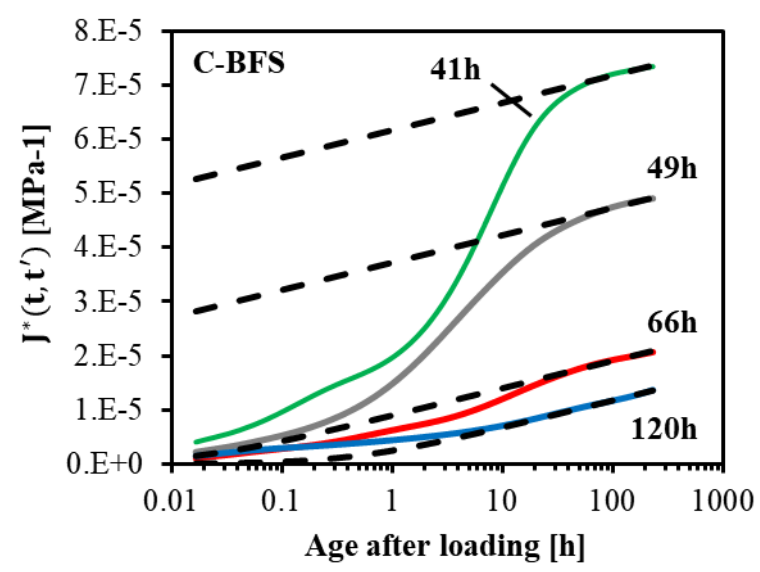

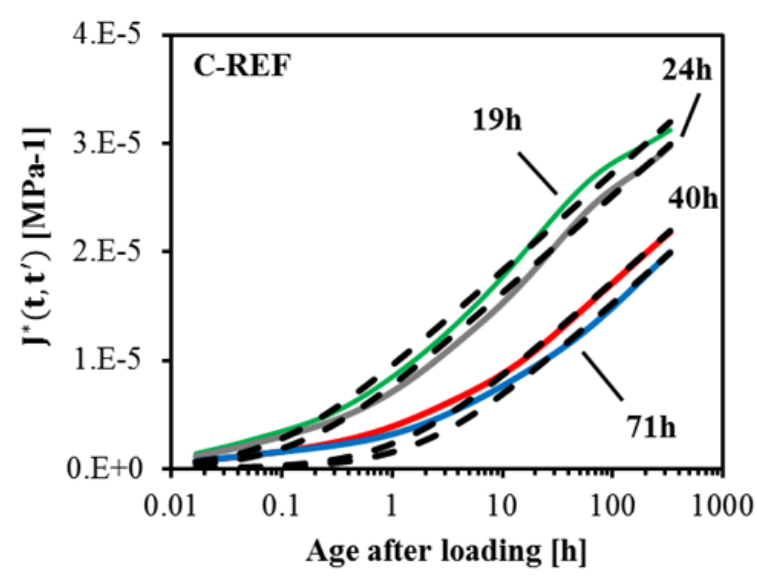

Figure 10 - Comparison between experimental creep curves (continuous lines) and creep curves predicted by an adapted version of the MC2010 (dashed lines).

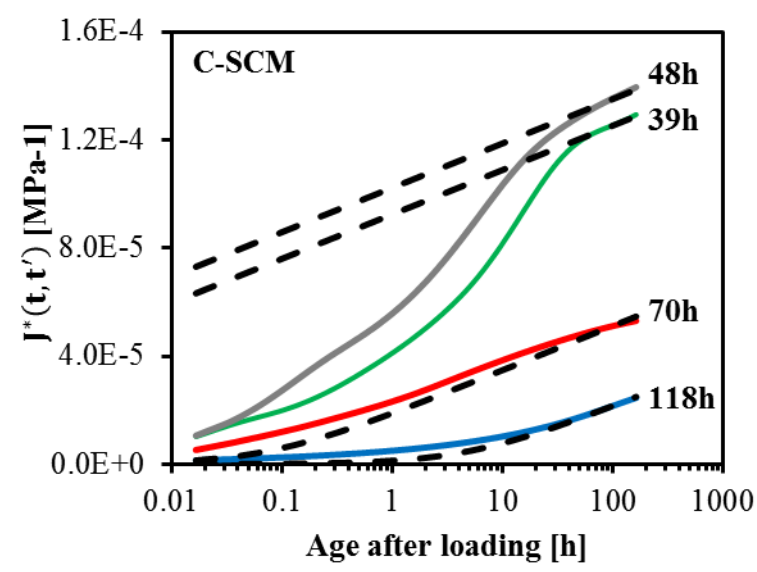

Figure 11 - Specific creep and adapted MC2010 (dashed lines) of the C-BFS and C-SCM compositions 


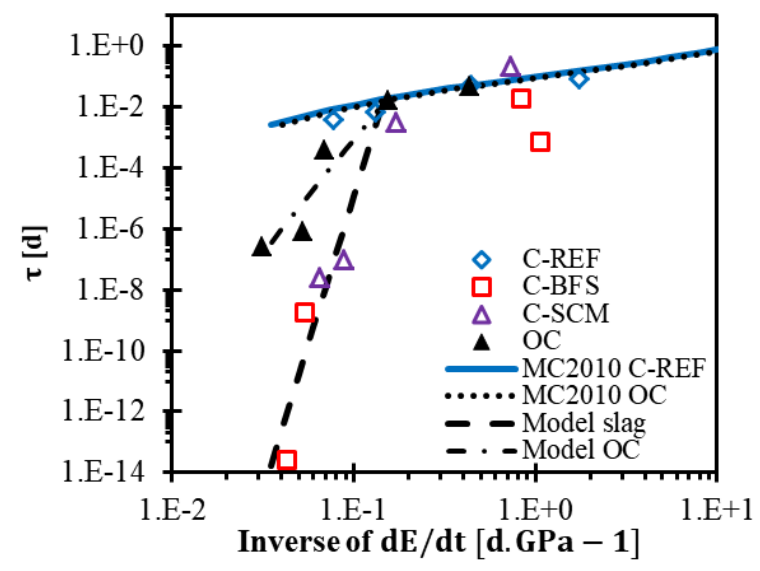

Figure 12 - Relation between the parameter $\boldsymbol{\tau}$ of the adapted MC2010 and the inverse of the E-modulus rate.

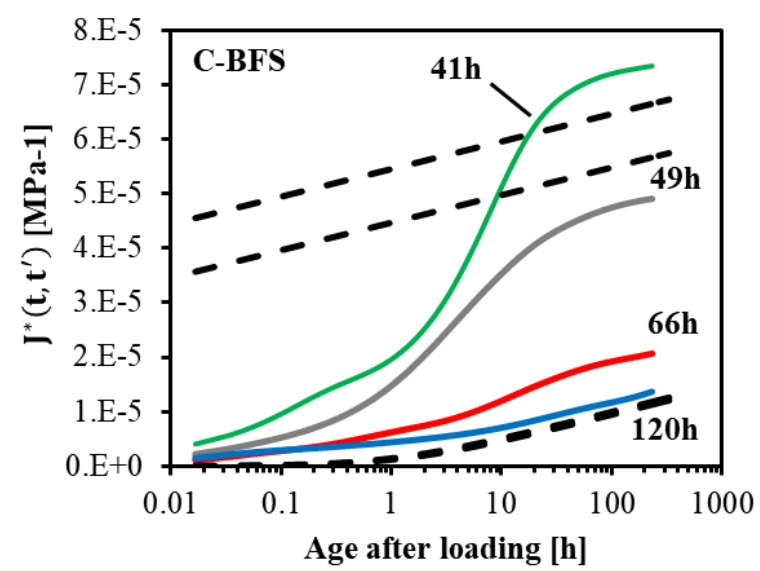

Figure 13 - Comparison between predicted value of the creep compliance obtained with the adapted MC2010 where the values of $\tau$ and C come from Equation 9 and Table 4 respectively (dashed lines) and experimental results (dashed lines) and experimental results (continuous lines) for the composition C-BFS. (continuous lines) for the composition C-SCM.

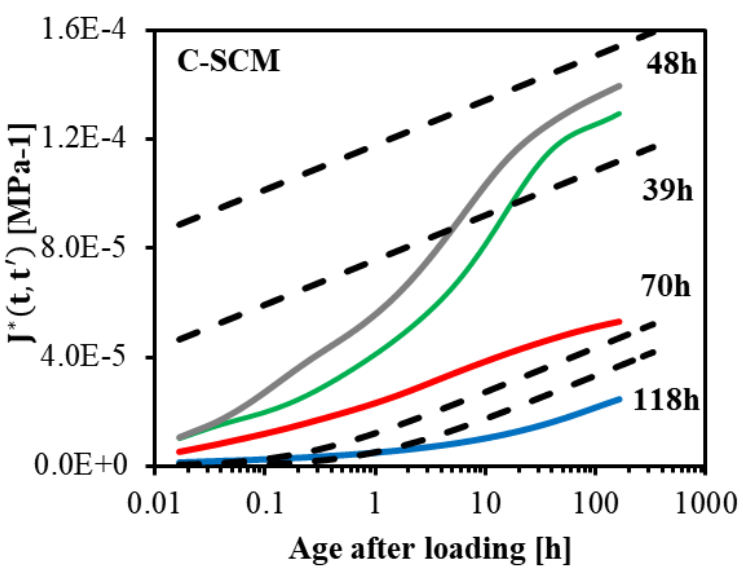

Figure 14 - Comparison between predicted value of the creep compliance obtained with the adapted MC2010 where the values of $\tau$ and C come from Equation 9 and Table 4 respectively 

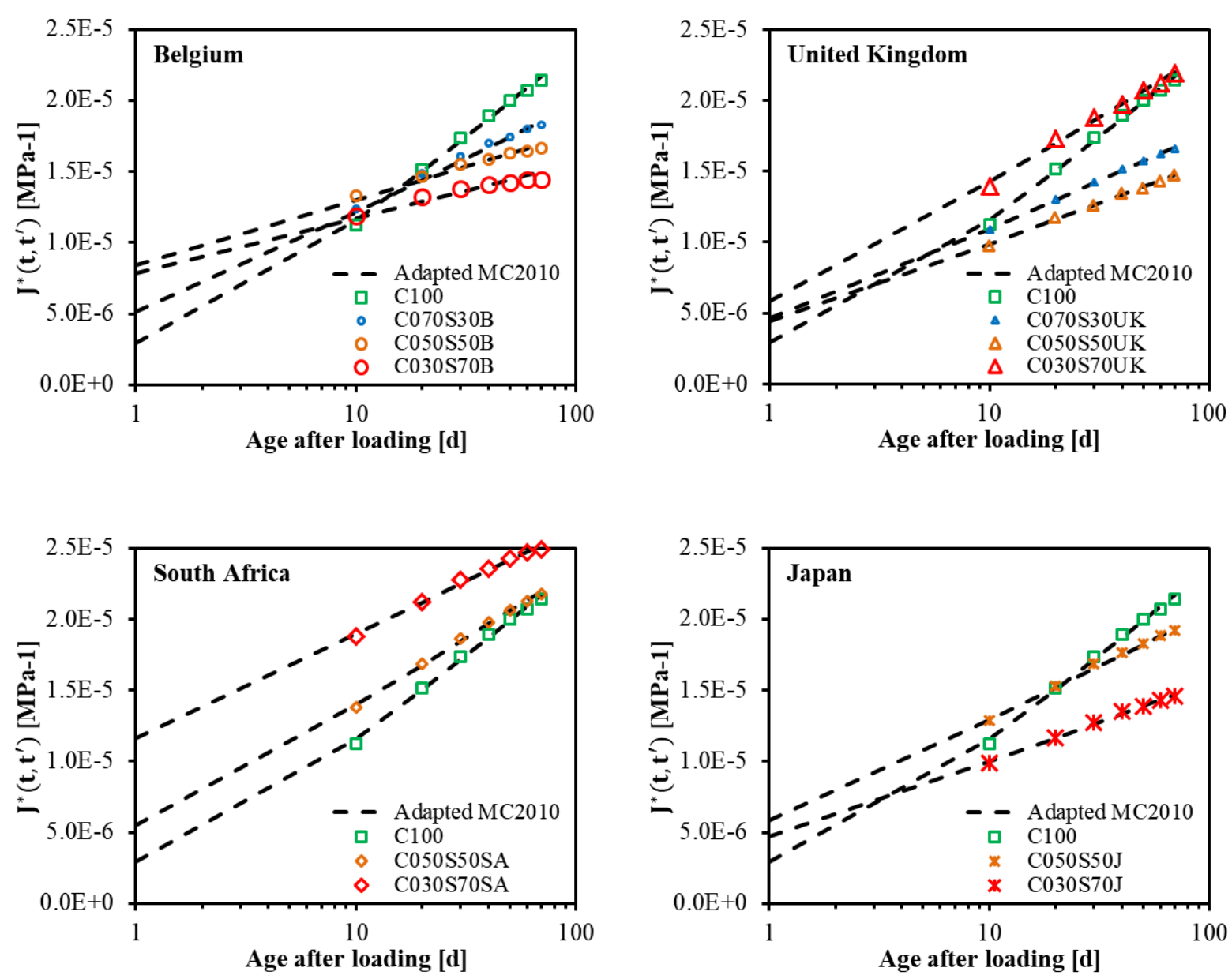

Figure 15 - Specific creep function and adapted MC2010 (dashed lines) of concrete compositions with different slag content and origin [26]. 


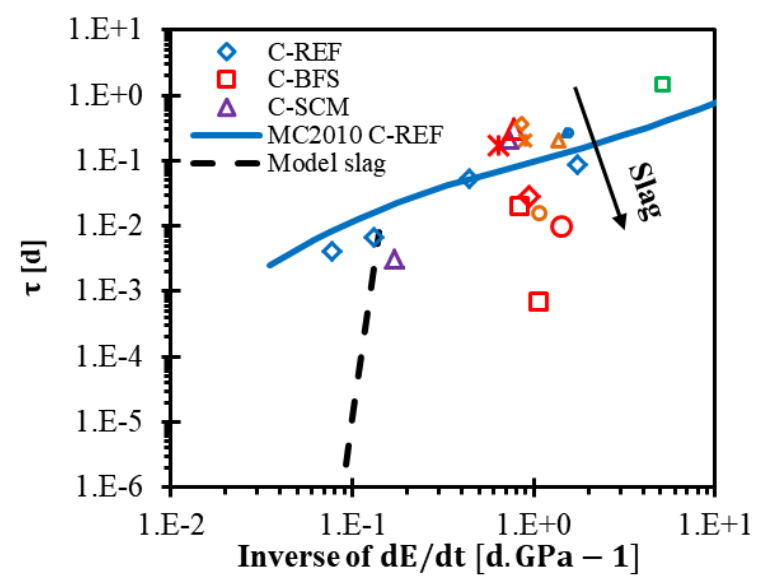

Figure 16 - Relation between the parameter $\boldsymbol{\tau}$ of the adapted MC2010 and the inverse of the time derivative of the E-modulus for concretes with different slag type and slag content. Results are compared to very early age and early age results presented in section 5.1. Results coming from Brooks, et al. [26] used the same legend marks as in Figure 15.

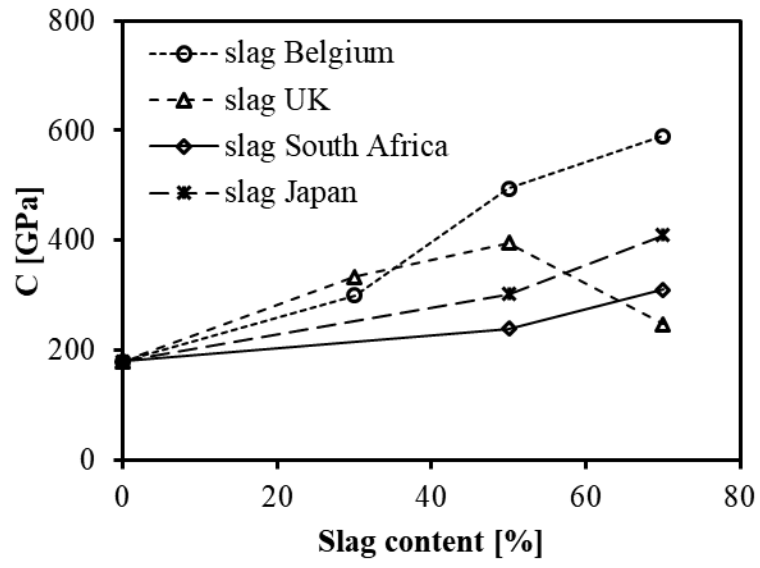

Figure 17 - Relation between the parameter $\mathbf{C}$ of the adapted MC2010 and the slag content for concrete with different type of slag. 

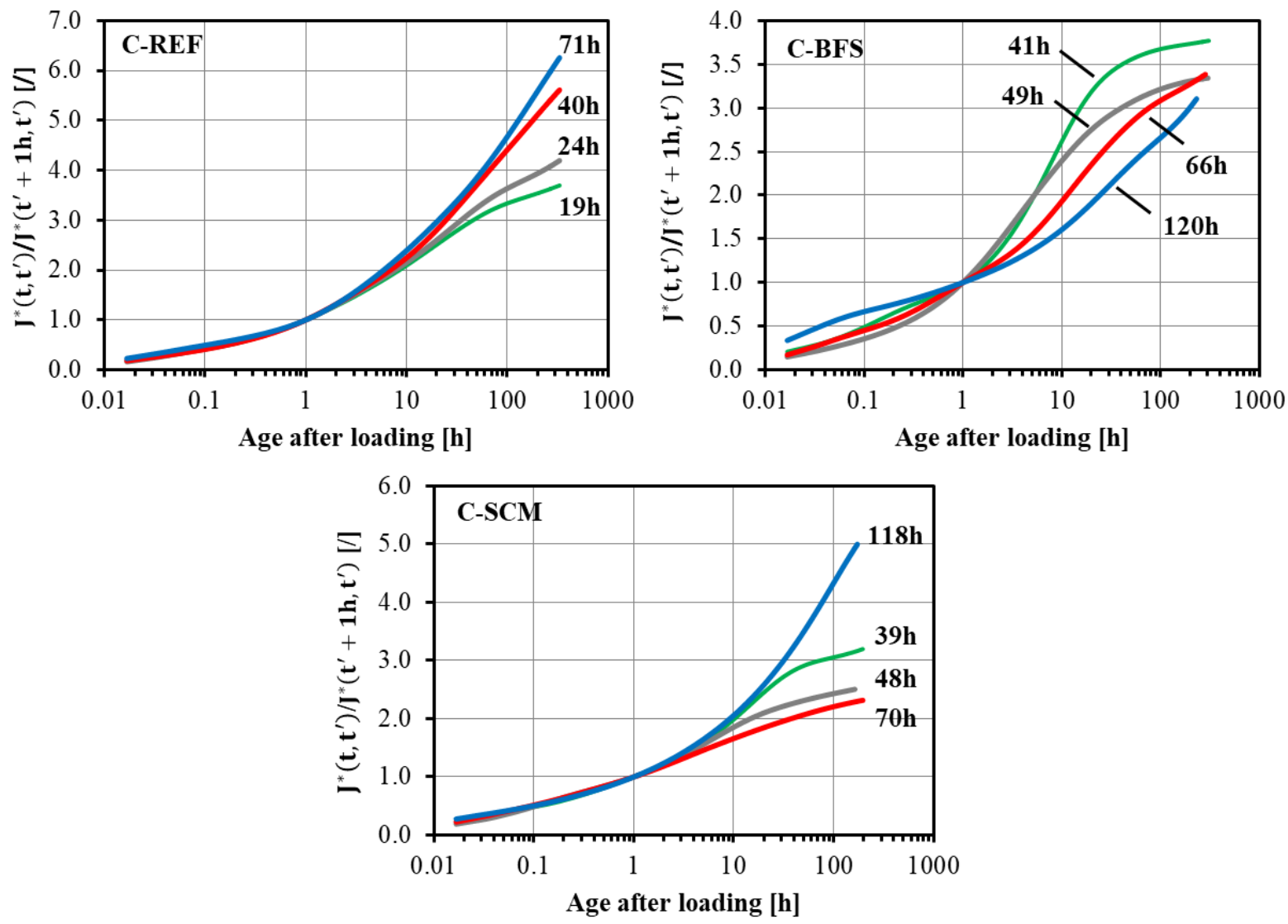

Figure A.1 - Specific creep curves normalized at an age after loading of 1 hour

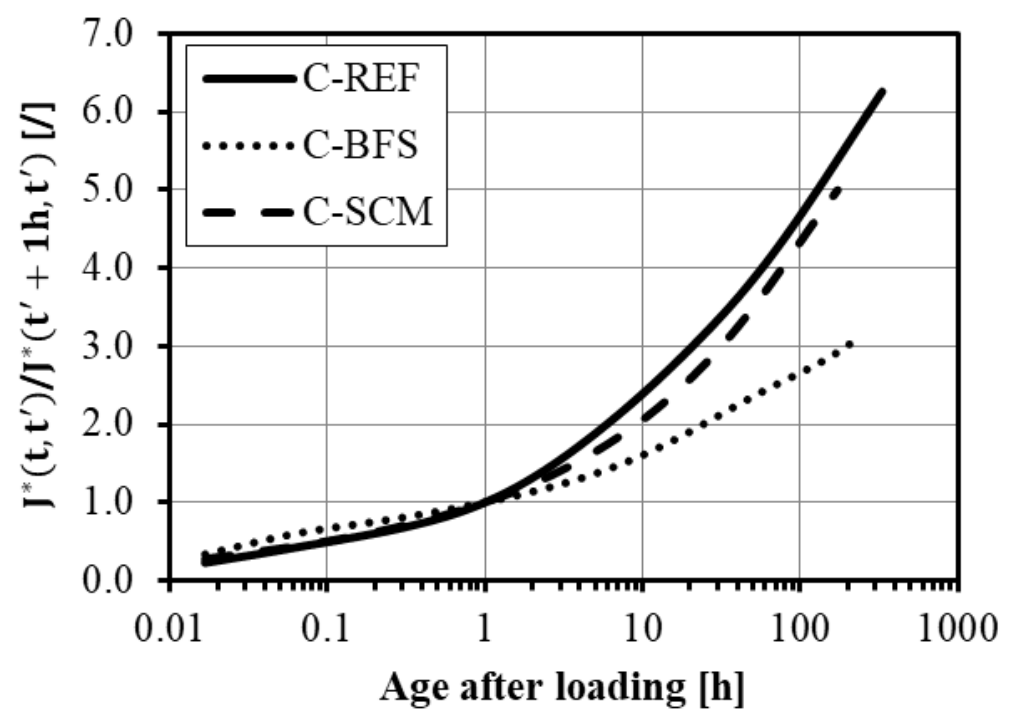

Figure A.2 - Specific creep curves normalized at an age after loading of 1 hour for an advancement degree of reaction at loading of 0.7 